OPEN ACCESS

Edited by:

Cristina Vassalle

Gabriele Monasterio Tuscany

Foundation (CNR), Italy

Reviewed by:

Yvonne Louwers,

Erasmus Medical Center, Netherlands

Mark Andrew Lawson,

University of California, San Diego,

United States

*Correspondence:

Carmen Elena Condrat

drcarmencondrat@gmail.com

${ }^{t}$ These authors have contributed

equally to this work

Specialty section:

This article was submitted to

Translational Endocrinology,

a section of the journal

Frontiers in Endocrinology

Received: 15 October 2020

Accepted: 04 January 2021

Published: 18 February 2021

Citation:

Duică F, Dănilă $C A$,

Boboc AE, Antoniadis $P$,

Condrat CE, Onciul S, Suciu N,

Crețoiu SM, Varlas VN and Cretoiu D (2021) Impact of

Increased Oxidative Stress on

Cardiovascular Diseases in Women With Polycystic Ovary Syndrome.

Front. Endocrinol. 12:614679. doi: 10.3389/fendo.2021.614679

\section{Impact of Increased Oxidative Stress on Cardiovascular Diseases in Women With Polycystic Ovary Syndrome}

Florentina Duică ${ }^{1 \dagger}$, Cezara Alina Dănilă ${ }^{1 \dagger}$, Andreea Elena Boboc ${ }^{1}$, Panagiotis Antoniadis ${ }^{2}$, Carmen Elena Condrat ${ }^{1,3^{*}}$, Sebastian Onciul ${ }^{4}$, Nicolae Suciu ${ }^{1,5,6}$, Sanda Maria Creţoiu ${ }^{7}$, Valentin Nicolae Varlas ${ }^{8,9}$ and Dragoș Creţoiu ${ }^{1,7}$

${ }^{1}$ Fetal Medicine Excellence Research Center, Alessandrescu-Rusescu National Institute for Mother and Child Health, Bucharest, Romania, ${ }^{2}$ Division of Molecular Diagnostics and Biotechnology, Antisel RO SRL, Bucharest, Romania, ${ }^{3}$ Doctoral School of Carol Davila University of Medicine and Pharmacy, Bucharest, Romania, ${ }^{4}$ Department of Cardiology, Clinical Emergency Hospital, Bucharest, Romania, ${ }^{5}$ Division of Obstetrics, Gynecology and Neonatology, Carol Davila University of Medicine and Pharmacy, Bucharest, Romania, ${ }^{6}$ Department of Obstetrics and Gynecology, Polizu Clinical Hospital, Alessandrescu-Rusescu National Institute for Mother and Child Health, Bucharest, Romania, ${ }^{7}$ Department of Cell and Molecular Biology and Histology, Carol Davila University of Medicine and Pharmacy, Bucharest, Romania, ${ }^{8}$ Department of Obstetrics and Gynecology, Filantropia Clinical Hospital, Bucharest, Romania, ${ }^{9}$ Faculty of Dental Medicine, Carol Davila University of Medicine and Pharmacy, Bucharest, Romania

Polycystic ovary syndrome (PCOS) is a complex disorder that affects around 5\% to 10\% of women of childbearing age worldwide, making it the most common source of anovulatory infertility. PCOS is defined by increased levels of androgens, abnormal ovulation, irregular menstrual cycles, and polycystic ovarian morphology in one or both ovaries. Women suffering from this condition have also been shown to frequently associate certain cardiovascular comorbidities, including obesity, hypertension, atherosclerosis, and vascular disease. These factors gradually lead to endothelial dysfunction and coronary artery calcification, thus posing an increased risk for adverse cardiac events. Traditional markers such as C-reactive protein (CRP) and homocysteine, along with more novel ones, specifically microRNAs (miRNAs), can accurately signal the risk of cardiovascular disease (CVD) in PCOS women. Furthermore, studies have also reported that increased oxidative stress (OS) coupled with poor antioxidant status significantly add to the increased cardiovascular risk among these patients. OS additionally contributes to the modified ovarian steroidogenesis, consequently leading to hyperandrogenism and infertility. The present review is therefore aimed not only at bringing together the most significant information regarding the role of oxidative stress in promoting CVD among PCOS patients, but also at highlighting the need for determining the efficiency of antioxidant therapy in these patients.

Keywords: polycystic ovary syndrome, cardiovascular disease, oxidative stress, C-reactive protein, homocysteine, miRNA 


\section{INTRODUCTION}

Assessment of the clinical interaction between cardiovascular diseases and other interrelated pathophysiological conditions, such as polycystic ovary syndrome (PCOS), in terms of molecular and cellular changes, common biochemical and immunological pathways leading to the development of these diseases, have been intensively studied in the latest decades. To this extent, it has been shown that a variety of cardiovascular diseases (CVD) have heterogenous pathophysiologic mechanisms, where oxidative stress (OS) has been considered as one of the potential etiologies.

Under normal conditions, when the body is not subjected to a high level of oxidative stress, there is a fine balance at the physiological intracellular level of reactive oxygen species (ROS), which is maintained at low levels by various antioxidant systems. A basal concentration of ROS is essential for performing pivotal cellular functions such as gene expression or complex processes involved in signal transduction pathways $(1,2)$. Dysregulation of the fine balance between ROS and antioxidants at cellular level leads to the occurrence of oxidative stress that has been demonstrated to be involved in a series of pathological conditions, including cardiovascular diseases and inflammatory processes, known to be associated with a high ROS levels. Excessive ROS concentrations act on cell macromolecules by promoting cell necrosis and apoptosis, thus affecting the normal course of multiple cellular functions $(1,3-6)$.

With regard to the female reproductive tract, although ROS indeed play certain physiological roles, including the modulation of several functions such as ovarian steroidogenesis, corpus luteal function and luteal regression, fertilization, and the development of the early embryo, numerous studies have demonstrated the pathological effects of these molecules, involved in a multitude of diseases (7). Further on, in relation to the mechanisms by which oxidative stress affects the cardiac function at cellular level, it has been shown that the occurrence of hypertension may be due to the process of vasoconstriction that takes place as a result of a decreased availability of nitric oxide due to increased ROS levels, concentrations which further impact the cardiac function by negatively influencing calcium signals, thus leading to arrhythmia. Additionally, it has been speculated that the increase in ROS levels could also influence cardiac remodeling and atherosclerotic plaque formation $(1,8)$. Although several studies have evaluated the correlation between cardiovascular diseases and PCOS, the association of this syndrome with subclinical and/or clinical forms of cardiovascular disease, independent of the risk factors common to the two diseases, the exact interrelationship between these conditions has not been clearly elucidated.

PCOS is a disease that presents heterogeneous clinical variants, in which the pathogenesis involves the existence of several cardiometabolic abnormalities such as metabolic syndrome, glucose intolerance, dyslipidemia, hypertension, diabetes, all of which are also risk factors for CVD diseases (9, 10). Furthermore, PCOS is characterized by polycystic ovarian morphology that leads to ovarian dysfunction such oligo- or anovulation, where the central neuroendocrine systems perform an important role, due to excessive luteinizing hormone (LH) and gonadotropin-releasing hormone $(\mathrm{GnRH})$ levels and relative follicle-stimulating hormone (FSH) deficiency, that contribute to the ovarian hyperandrogenemia and altered folliculogenesis, characteristic features of PCOS (11-13).

PCOS is a heterogenous syndrome that manifests through changes in the metabolic balance in which mitochondrial dysfunctions have been shown to facilitate the progression and occurrence of various complications of this disease (13). Although the etiology and pathophysiology of PCOS are not yet fully elucidated, it is currently considered that the main pathophysiological mechanism leading to this syndrome is the excess of androgen hormones, which results in metabolic, reproductive, and not least cosmetic changes, consisting of an increased body mass index due to a predisposition to obesity, as well as changes in the appearance of the skin due to acne outbreaks (12-15). Moreover, recent studies have highlighted the link between the pathogenesis of PCOS and chronic inflammatory status, with published data showing that numerous inflammatory markers are elevated in women suffering from PCOS $(13,16,17)$. An additional possible cause of PCOS has been shown to be oxidative stress that could cause genetic changes such as point mutations, DNA strand breaks, aberrant DNA cross-linking, DNA-protein cross-linking, and DNA methylation, ultimately leading to the silencing of certain tumor suppressor genes (18-22).

\section{PCOS-Definition}

PCOS is a heterogeneous ailment described in women of childbearing age, characterized by ovulatory dysfunction, androgen excess, and polycystic ovarian morphologic features $(23,24)$. Also known as the Stein-Leventhal syndrome, it is a common endocrinopathy among women of reproductive age. PCOS affects $6 \%$ to $15 \%$ of women at the reproductive age, depending on diagnostic criteria $(25,26)$. The Rotterdam criteria (2013) are the most commonly used criteria to diagnose PCOS, and include the following: ovulation disorder, hyperandrogenism diagnosed by biochemical testing and/or clinical aspects, and ovarian volume over $10 \mathrm{ml}$ or 12 or more ovarian cysts. The diagnosis can be established when two of the three conditions are fulfilled (27). Based on these criteria, four PCOS phenotypes can be detected, namely ovulation disorders, polycystic ovary, and hyperandrogenism, making up the classic phenotype, normal ovarian ultrasonography with hyperandrogenism and ovulation disorder, polycystic ovary ultrasonography image and hyperandrogenism, with no ovulation abnormalities, and no evidence of hyperandrogenism, but with polycystic ovary ultrasonography image and ovulation disorders $(28,29)$. Several endocrinopathies can mimic PCOS, such as Cushing's syndrome, non-classic adrenal hyperplasia, drug-induced androgen excess, and androgen-producing tumors (30). Ovulatory dysfunction can further be found in conditions like hyperprolactinemia or thyroid dysfunction (31). Therefore, in order to proper diagnose PCOS, these disorders need to be excluded.

PCOS is characterized by the overproduction of ovarian androgen hormones, especially testosterone, as a result of an 
excessive production of $\mathrm{LH}$ in the pituitary gland or due to hyperinsulinemia, if the ovaries are sensitive to insulin. Common symptoms noticed in women with PCOS are infertility, signs of androgen excess such as hirsutism, virilization, acne, alopecia, and menstrual irregularities, including amenorrhea and dysfunctional bleeding (32). Women with PCOS also have an increased prevalence of certain comorbidities, such as dyslipidemia, excess weight, metabolic syndrome, type 2 diabetes, and hypertension. Along with other features such as chronic low-grade inflammatory state and endothelial dysfunction, PCOS poses an elevated risk of developing cardiovascular disorders (33).

\section{PCOS-Pathophysiology}

There are many hypotheses regarding the pathophysiology of PCOS, including among them ovarian hyperandrogenism, follicles resistant to rupture due to shell thickness, hypersecretion of luteinizing hormone, increased anti-Mullerian hormone (AMH), which is a blocker paracrine factor for follicular development, and hyperinsulinemia (34). These abnormalities can appear due to hormonal, metabolic, or even toxic factors occurring during the embryonic stage and/or in the early development of the female gonad, or because of certain epigenetic changes (35). The genetic basis of PCOS is suspected on the grounds of the aggregation of this syndrome in families, since it has been shown that within firstdegree relatives, about 20 to $40 \%$ of women also have the disorder $(23,34,36,37)$.

\section{Gonadotropins}

Gonadotropin-releasing hormone $(\mathrm{GnRH})$ neuropeptides released from neurons into the portal vein and median eminence stimulate the adenohypophysis gland to secrete gonadotropins, which mediate ovarian steroidogenesis and folliculogenesis. The follicle-stimulating hormone (FSH) binds to FSH receptor on the granulosa cells and stimulates follicular maturation and ovulation (38). On the other hand, the luteinizing hormone $(\mathrm{LH})$ stimulates steroidogenesis, follicular growth, and corpus luteum formation $(39,40)$. Anovulation is determined by inappropriate gonadotropin secretion. Specifically, modified pulsatility of GnRH consisting of elevations in the amplitude and frequency of secretion, generates an increased production of $\mathrm{LH}$ compared to that of FSH. It is unknown whether hypothalamic dysfunction is a determining cause of PCOS or is caused by an abnormal steroid feedback. In both cases, the level of LH is reported to be high, while the LH/FSH ratio is increased to over $2 / 1$ (36).

The impact of peripheral hormones on the brain function in the pathogenesis of PCOS has been explained through four suggested hypotheses. The first hypothesis is based on the negative feedback of steroid hormones which appears after setting up changes of the critical neuronal circuits determined by hyperandrogenism (40). The second hypothesis revolves around the hyperinsulinemia that stimulates the activity of GnRH neurons and the response of the pituitary gland to $\mathrm{GnRH}$ (41). The third hypothesis refers to the low concentration of progesterone in serum that is followed, in PCOS, by anovulation, which eventually eliminates the influence of the progesterone negative feedback on the release of GnRH (42). The fourth hypothesis states the function of the pulse generator of $\mathrm{GnRH}$ that reduces the activity of $\mathrm{GnRH}$ inhibitors $(40,43)$. Overall, the hypothalamic-pituitary-gonadal axis remains one of the principal regulators of female reproduction, its dysfunction leading to ovulation disorders.

\section{Hyperandrogenism}

A fundamental characteristic of PCOS is the increased production of androgens in ovaries, due to excessive activity in the theca cells stimulated by intraovarian or extraovarian factors (44). LH and insulin stimulate the production of androgens, determining elevated levels of dehydroepiandrosterone (DHEAS) and testosterone (36) (Figure 1). High levels of free testosterone were noticed in about $70 \%$ to $80 \%$ of patients with PCOS, while $25 \%$ to $65 \%$ expressed elevated DHEAS levels. This leads to increased estrone levels by peripheral conversion mechanism, which converts androgens to estrogens using aromatase. Furthermore, low levels of sex hormone-binding globulin (SHBG) were reported in women diagnosed with PCOS (36). Liver synthesis of SHBG is reduced by insulin as well as progestins, androgens, corticoids, and growth hormones (45). Reduced SHBG production leads to lower levels of bound circulating androgens, thus resulting in more available androgens capable of binding to organ receptors. Consequently, clinical hyperandrogenism is determined by high levels of free testosterone, although total testosterone might be within the normal range (46).

Exposure to androgens throughout fetal development has been speculated as another reason for hyperandrogenism determining the phenotypes of PCOS in adulthood (47). In this regard, there are four hypotheses for the exposure to additional androgens during the embryo stage. Firstly, the evolution of the hypothalamic-pituitary axis simultaneously with certain hypothalamic-pituitary axis disorders in embryonic development are thought to increase the production of androgen hormones (48). Secondly, in mothers with PCOS, the placenta is limitedly capable of aromatization and increasing of SHBG concentration, thus causing the fetus to receive maternal androgens through the placenta (49). The third hypothesis suggests a fatal genetic disorder with undifferentiated ovaries that can be the source of increased androgen production (35). The fourth hypothesis refers to malformations that increase the androgen production, such as hyperplasia of the adrenal glands (50). Either way, in order to diagnose PCOS in women, one must look at the biochemical androgen profile, which includes free and total testosterone, SHBG, DHEAS, 17-hydroxy-progesterone and the free androgen index (FAI), estimated as the total testosterone level divided by SHBG and multiplied by 100 (51).

The steroidogenic cells of the adrenal cortex and the ovary stand at the origin of the hyperandrogenemia that characterizes PCOS, using similar enzymes for steroidogenesis (52). The Cytochrome P450 Family 19 Subfamily A Member 1 (CYP19A1) gene encodes the aromatase, enzyme which turns androgens into estrogens. In the ovarian follicles, reducing the activity of aromatase leads to hyperandrogenism, and a positive correlation between the incidence of PCOS and mutations in this gene 


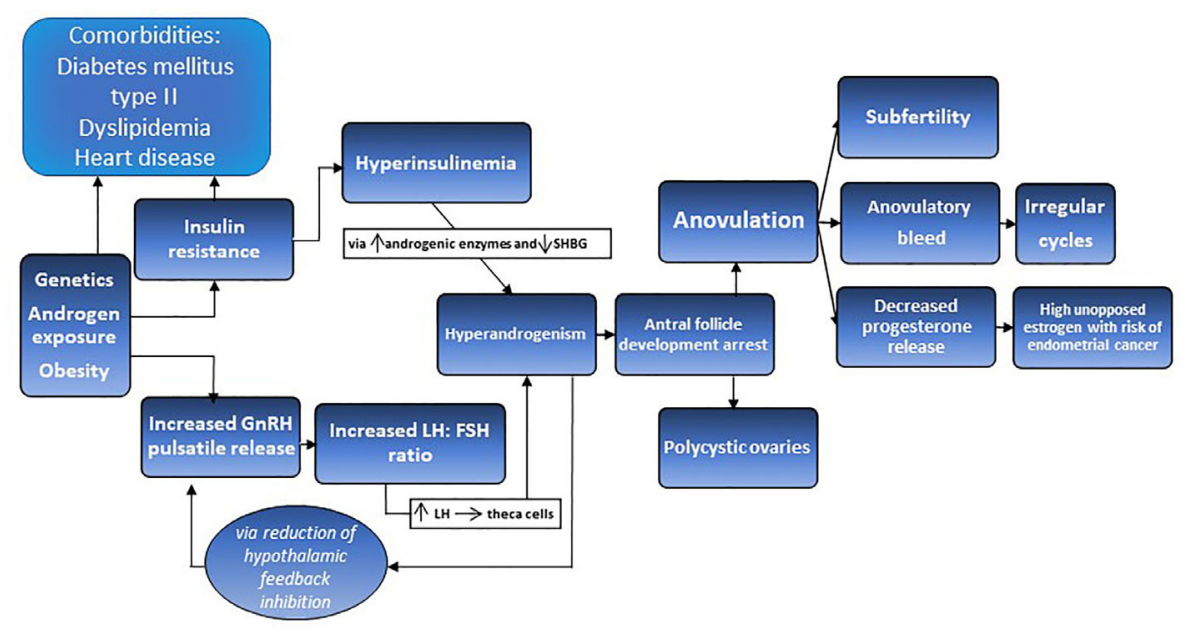

FIGURE 1 | The proposed pathophysiology of PCOS is a synergistic relationship between perturbed gonadotrophin releasing hormones (GnRH) pulsatility and insulin resistance, accompanied by hyperinsulinemia and hyperandrogenism leading to antral follicle development arrest, anovulation, irregulate cycles, subfertility, and polycystic ovaries.

has been observed (53). Furthermore, an androgen excess has been indicated to determine hypertension by stimulating the expression of adipose tissue aromatase $(54,55)$.

\section{Hyperinsulinemia}

Insulin is the hormone primarily responsible for lipogenesis and glucose homeostasis. Insulin has effects on fat, protein metabolism, carbohydrates, while also acting as a mitogenic hormone (56). The ovary and adrenal cortex are steroidogenic tissues in which insulin promotes steroidogenesis by potentiating the cognate trophic hormones (57). Insulin resistance associated with compensatory hyperinsulinemia determines excessive adrenal and/or ovarian androgen secretion and decreases the synthesis of SHBG in the liver, thus resulting in an increase of circulating testosterone concentration. Intrinsic insulin resistance is characteristic of women with PCOS independent of the magnitude of androgen levels and extent of obesity, with lean PCOS patients also experiencing it (28). Insulin resistance leads to reduced glucoseuptake response in spite of high insulin levels. This is the result of decreased insulin sensitivity due to abnormal signal transduction at receptor and post-binding level (36).

Alternate theories emphasize the fact that LH levels negatively correlate with insulin levels in women, an aspect demonstrated experimentally in both normal and PCOS women under euglycemic/hyperinsulinemic clamps $(58,59)$. Loss of negative feedback in the hypothalamus elevates $\mathrm{LH}$, which may drive increased androgen production, but it is androgen that results in insulin resistance $(60,61)$. Elevated androgen levels positively correlate with LH levels, suggesting a failed compensatory mechanism prompting elevated LH output. Thus, loss of negative feedback in the hypothalamus can lead to both PCOS and increased heart disease, which may also be aggravated by increased obesity (62). The paradox of insulin signaling witnessed in PCOS is that the adipose tissue, liver, and skeletal muscles exhibit insulin resistance, whereas the pituitary and steroidproducing tissues retain insulin sensitivity. This aspect has been illustrated by observing the different actions of insulin in granulosa lutein cells from patients with PCOS and anovulation (28). In women with PCOS, the prevalence of metabolic syndrome is approximately threefold higher and is defined as the association of hyperglycemia, obesity, dyslipidemia, and hypertension (63). However, the definition of metabolic syndrome is incomplete in adolescents, being characterized by a combination of low highdensity lipoprotein (HDL) cholesterol levels, high triglyceride concentrations, increased waist circumference, elevated fasting blood glucose, and hypertension for age $(28,64,65)$.

\section{Ovaries}

Ovulation results from coordinated signaling by the hypothalamuspituitary axis, ovarian granulosa cells, ovarian theca cells, and the developing follicle (66). In women with PCOS, this process malfunctions because of the abnormal development and failure in selecting a dominant follicle, thus inducing anovulation (67). The ovulatory dysfunction is characterized by increased activation of the follicles, followed by arrested growth before the maturation of these follicles can occur. Furthermore, PCOS follicles also have lower rates of atresia, which may explain why premature depletion of the follicular pools seldom occurs in the ovaries of these women (68). Due to anovulation, progesterone is lacking, thus leading to chronic estrogen exposure. This has an impact on the endometrium by constant mitogenic stimulation with endometrial thickening which leads to unpredictable bleeding or endometrial cancer (69).

In normal folliculogenesis, growth factors such as growth differentiation factor 9 (GDF-9) and bone morphogenetic protein 15 (BMP15), also referred to as oocyte-secreted growth factors (OSFs), aid in the development from primordial to primary stage follicles, while subsequent stages, up to the selection of the dominant follicle are regulated by FSH to (70). 
Throughout folliculogenesis, insulin and androgens have a synergistic aspect with LH, which exerts its effect from the middle to the late follicular stage (71). The equivalence between $\mathrm{AMH}$ and FSH may play a primary role in the aromatase activity, both during and after dominant follicle selection. Moreover, increased estradiol emission by the dominant follicle suppresses FSH levels, leading to subordinate follicle dissolution resulting in mono-ovulation (72). Under excessive androgen exposure, accelerated early follicular growth in PCOS tends to take place, leading to small-follicle occurrence. Decreased OSFs levels further lead to intensified early folliculogenesis (73). Further on, small follicle excess promotes high $\mathrm{AMH}$ levels, which in turn mediate follicle responsiveness to FSH (74). To this extent, low FSH responsiveness and premature granulosa cell luteinization denature the dominant follicle selection, producing follicular arrest (75). High insulin levels can further induce premature luteinization along with $\mathrm{LH}$ receptor expression (76).

Follicular defects associated with PCOS are defined by early and accelerated follicular growth as well as distortion in the subsequent stages in relation to dominant follicle selection, leading to follicular arrest (77). In this regard, Webber et al. have reported a greater density of small preantral, especially primary follicles in analyzed ovarian biopsies belonging to women diagnosed with PCOS in comparison with control groups (78). Atresia deceleration, later demonstrated by the same team of researchers, may answer for the increased recruitment and explain why premature follicle depletion does not occur in polycystic ovary (79). Arrested follicle development in women with PCOS can be explained by the relatively low levels of circulating FSH, which hinder the normal maturation process (80). Additionally, LH hypersecretion is detrimental to ovulation and follicular growth, since it determines decreasing FSH sensitivity, thus contributing to the premature luteinization of granulosa cells (32).

Anovulation can also be determined by altered $\mathrm{GnRH}$ pulsatility and improper gonadotropin secretion, both leading to menstrual irregularity (81). Moreover, anovulation can also be facilitated by insulin resistance, as many anovulatory patients diagnosed with PCOS express ovulatory cycles after treatment with insulin sensitizers such as metformin $(82,83)$. Increased intraovarian androgens from large antral follicles may also cause anovulation in patients with PCOS, fact which is supported by the improvement of menstrual regularity in patients who underwent laparoscopic ovarian drilling or ovarian wedge resection (36).

\section{Inflammation}

Low-grade systemic inflammation associated with PCOS is indicated by the high levels of inflammatory markers such as interleukin-18 (IL-18), C-reactive protein (CRP), white blood count, and monocyte chemoattractant protein-1 (MCP-1), along with increased oxidative stress and endothelial dysfunction (84). These inflammatory markers stimulate the proliferation of theca cells, while also promoting steroidogenesis, and contributing to follicular atresia and hyperandrogenemia (13).

Hyperglycemia further plays a role in PCOS-related inflammation, due to mononuclear cells utilizing glucose as a redox substrate, thus leading to high levels of ROS and inducing oxidative stress (85). ROS production by immune cells as a result of oxidative stress plays a primordial role in both the development and progression of endothelial dysfunction, which significantly contributes to the occurrence of arterial hypertension along with other cardiovascular diseases. Furthermore, insulin resistance and chronic inflammation play important roles in the etiopathogenesis of diabetes mellitus type II and metabolic syndrome, common comorbidities among PCOS women $(33,86)$.

\section{CARDIOVASCULAR DISEASE IN PCOS}

While significant improvement in the incidence and general outcome of cardiovascular diseases has been observed in the past decades, they go on being the leading cause of death among women worldwide $(87,88)$. Furthermore, preventive care including counseling and prophylactic treatment is less likely to be offered to women than men with similar atherosclerotic cardiovascular disease risk $(87,89)$, while medical management of these patients tends to be less vigorous, thus more rarely achieving optimal results $(90,91)$. While most cardiovascular risk factors in women overlap with those in men, several circumstances remain characteristic of women $(92,93)$, as it can be seen outlined in Figure 2.

Cardio-metabolic disturbances have been found in women with PCOS regardless of age, posing significant risks for the occurrence of CVD. These disturbances are represented primarily by atherogenic dyslipidemia, hypertension, obesity, along with insulin resistance, impaired glucose tolerance and type II diabetes $(94,95)$. The association between PCOS and CVD has been related to this partial overlapping of risk factors. While PCOS is influenced by race, BMI and age, with symptoms becoming less thunderous with increasing age and most of them disappearing after the onset of menopause, cardio-metabolic disorders can, however, continue to pose a threat to the patients' health $(94,96-99)$. If earlier studies regarding the higher risk of CVD in women with PCOS could not establish its absoluteness (100), more recent data confirm that the metabolic dysfunction typical of women with PCOS leads to a definite increase in CVD events (101-103).

\section{Hypertension}

The pathophysiology of hypertension in PCOS is multifactorial, depending on factors such as obesity, hyperandrogenism, elevated sympathetic nervous system activity, and insulin resistance (104). Several studies indicated that patients with PCOS are more likely to develop hypertension as opposed to the normal population. However, this fact is somewhat unclear, since PCOS is associated with obesity as well, which also represents a significant risk factor for hypertension. Therefore, the interpretation of these studies is rather complicated, since obesity is a variable not usually considered in many types of research (105-111). Still, a meta-analysis performed by Amiri et al. showed that hypertension is more common in women with PCOS than in the control population. Moreover, they have 


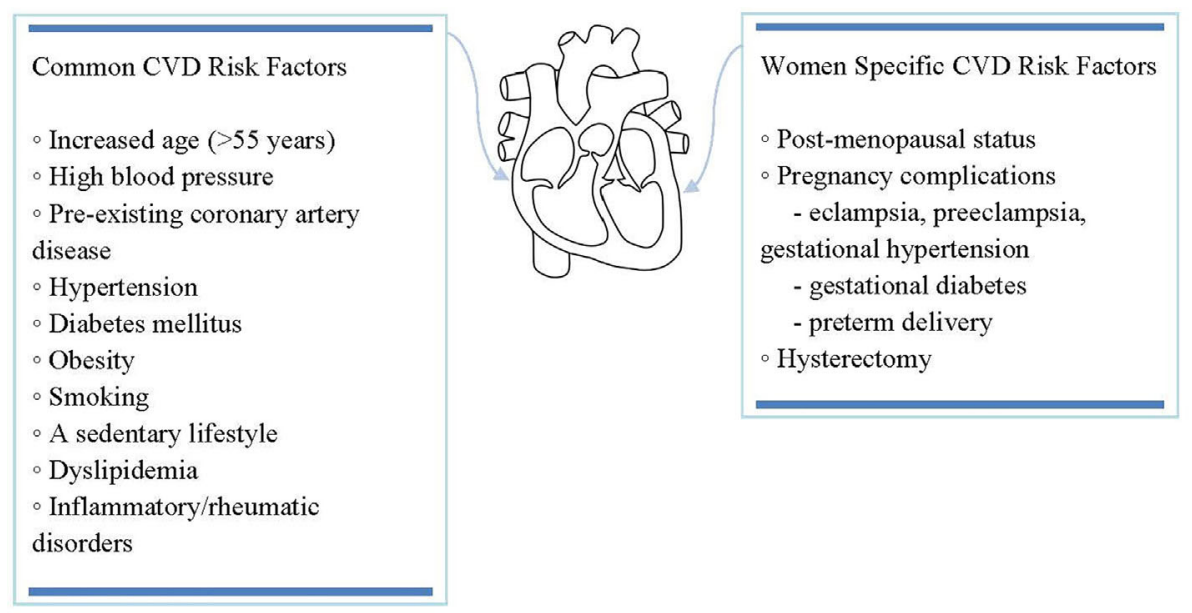

FIGURE 2 | While most cardiovascular risk factors in women overlap with those in men, several circumstances remain characteristic of women.

separately evaluated women during post-menopause and reproductive-age women with PCOS because, since it is well known that the prevalence of hypertension is higher with aging and with menopause onset. The result was that, even after adjusting diabetes mellitus and BMI variables, PCOS women during reproductive age were more likely to develop hypertension (112).

As mentioned previously, a significant risk factor for hypertension is represented by obesity. In this regard, it has been shown that the prevalence of obesity and overweight status among PCOS patients is $80 \%$ higher compared with non-PCOS women, with PCOS women associating BMIs over $30 \mathrm{~kg} / \mathrm{m}^{2}$ and higher waist-hip ratios (113), more commonly in Caucasian than Asian women (114). Obesity in females suffering from PCOS may be correlated with insulin resistance, which generates hyperinsulinemia that triggers ovarian steroidogenesis. This way, sex hormone-binding globulin production is downregulated and, as a consequence, the availability of free androgens is elevated, causing visceral accumulation of fat, thus facilitating central obesity (113-115). In PCOS patients, it was observed that a combination of factors like insulin resistance, obesity, and hyperandrogenism leads to an elevated sympathetic nervous system activity, each factor being a possible mediator of hypertension (116-118).

Deficiencies in the hypothalamic-pituitary axis produce an excessive secretion of LH and a low excretion of FSH, hormonal imbalance that leads to secretory changes in the inner sheath of ovarian follicles. In turn, an excess of androgenic hormones is released, which is responsible for both clinical and paraclinical signs of hyperandrogenism $(119,120)$. Numerous women with PCOS, especially those with hyperandrogenic phenotype, have various cardio-metabolic disturbances that increase the risk of developing hypertension $(121,122)$. One study demonstrated that, with age, almost half of women with PCOS improve due to the decrease of serum androgens as a consequence of adrenal and ovarian aging (123). Testosterone levels drop with age in both
PCOS and healthy women, the decrease being observed years before the onset of menopause (124). This fact may lead to a progressive reduction of CVD risk factors (125). However, the processes that determine the lowering of hypertension risk remain slightly vague. An analysis of daytime ambulatory blood pressure revealed that young and obese women suffering from PCOS had elevated blood pressure in comparison with non-PCOS females (107). Other variables that must be taken into consideration are background aspects of the individual such as ethnicity and race. To this extent, Lo et al. revealed that, even after adjusting for diabetes mellitus, age, and BMI, the prevalence of hypertension and/or high blood pressure was increased in black women with PCOS when compared to the Caucasian population, and among the latter, Hispanic and Asian women were the least affected (126).

\section{Atherosclerosis and Vascular Disease}

Dyslipidemia is a cardio-metabolic disturbance distinguished by high levels of LDL cholesterol and triglycerides and low levels of HDL cholesterol, found in both obese and lean women with PCOS $(127,128)$. This imbalance, together with obesity and insulin resistance, predisposes these females to a subclinical vascular disease characterized by intimal-medial thickening in the carotid arteries, coronary artery calcifications, and endothelial dysfunction (129-131). These modifications could put PCOS patients at risk for developing cardiac events, both fatal and nonfatal, as well as strokes (132).

Carotid intima-media wall thickness (cIMT) is a determination of the tunica media and tunica intima of the arteries, evaluated usually by ultrasound performed on large vessels close to the skin, as is the carotid artery. This measurement is utilized for the detection of atherosclerosis and for tracking its regression or progression, and it is correlated with the prevalence of myocardial infarction or stroke (133-139). cIMT is known to be associated with visceral adiposity, dyslipidemia, hyperinsulinemia, and raised systolic blood pressure, risk factors also encountered in 
PCOS (140-146). Meyer et al. performed a meta-analysis that showed that cIMT is elevated in females with PCOS compared with the control group, suggesting an elevated risk for accelerated atherosclerosis in PCOS patients (147). Talbott et al. further demonstrated that increased cIMT was noticed in females $\geq 45$ years, explaining that CVDs have long incubation periods, with metabolic disturbances occurring in young age converting into carotid damage by older age, and it seems that cIMT is more affected by the combination of age and PCOS than by aging alone (131).

The severity of coronary atherosclerosis is indicated by the coronary artery calcium (CAC) score, an independent risk marker for sudden cardiac death and myocardial infarction in both symptomatic and asymptomatic patients (148), with several studies focusing on elevated CAC scores in PCOS patients. For instance, Christian et al. performed a study that included premenopausal women at 30 to 45 years old suffering from PCOS and found a higher prevalence of elevated CAC scores in PCOS women than in the control group (149). Another study performed by Talbott et al. reported that elevated CAC had a higher prevalence among PCOS females between 40 and 61 years old (46\%) than the control group (31\%), even after controlling for BMI and age (150). Shroff et al. further conducted a research study designed to discover early-onset increased CAC score as an indicator of subclinical atherosclerosis in young and obese PCOS females (151). Compared with weight and age-matched controls, early coronary atherosclerosis was detected in young females suffering from PCOS. Due to the young age, the subjects in the study did not associate other CVD risk factors, therefore PCOS was speculated to contribute to the risk of elevated CAC scores (151).

It is broadly accepted that chronic inflammation is correlated with endothelial dysfunction. Abnormal morphology, disposition, and function of the adipose tissue in PCOS females are correlated with the generation of chemokines, cytokines, and low-grade inflammation, which lead to the activation of hypoxia-induced pathways, with the consequential reduction of adiponectin production (152). This pro-inflammatory condition is correlated with the progression of insulin resistance, thus promoting type II diabetes development along with increasing cardiovascular risk (153). Furthermore, it is presumed that androgens are mediators in the transformation of preadipocytes into mature adipocytes, while also having an impact on oxidative stress, lipid, and glucose metabolism $(99,154)$. Overall, females with PCOS, due to their underlying pathophysiology, could be at risk for cardiac and cerebrovascular disease. Contrasting results that were obtained during several studies prompted more research, especially in the form of longitudinal studies, focusing on cardiovascular assessment and follow-up of these women for a better understanding and management of PCOS complications.

\section{OXIDATIVE STRESS IN PCOS AND CVD}

At a biological level, oxidative stress refers to the physiological disturbances between free radical species such as ROS or reactive nitrogen species (RNS), and the body's ability to eliminate them.
Oxidative stress can also be defined as the discrepancy between signaling systems and redox control systems (155-157). Living organisms have developed several mechanisms to respond to oxidative stress by producing antioxidants. A change in the balance between oxidizing and antioxidant substances in favor of excess oxidants leads to oxidative stress. These systems include enzymes (superoxide dismutase, catalase, and glutathione peroxidase), antioxidant macromolecules (albumin, ceruloplasmin, and ferritin), antioxidant micro-molecules (ascorbic acid, $\alpha$-tocopherol, $\beta$-carotene, ubiquinone, flavonoids and glutathione, methionine, uric acid) bilirubin (1, 158-161).

ROS are highly reactive molecules with a very short lifespan, and are classified into two categories, namely non-radical species, including hydrogen peroxide ( $\mathrm{H} 2 \mathrm{O} 2)$, hypochlorous acid (HOCl-), ozone (O3-), lipid peroxides ( $\mathrm{LOOH})$, along with hydroperoxides $(\mathrm{ROOH})$, and radical species, consisting of superoxide anion $(\mathrm{O} 2 \bullet-)$, singlet oxygen $(1 \mathrm{O} 2)$, hydroperoxyl radical (HOO•), hydroxyl radical $(\bullet \mathrm{OH})$, with $\bullet \mathrm{OH}$ being considered the most important ROS (158). RNS on the other hand comprise a range of various chemical compounds derived from nitric oxide (NO) in the reaction of biologically generated free radicals that tend to form more stable species, a process that generates multiple biological effects (162). Free radical species are extremely unstable molecules that tend to gain stability by acquiring electrons from neighboring molecules such as nucleic acids, carbohydrates, proteins, and lipids, which leads to a cascade of chain reactions, that cause cell damage $(155,163-$ 167). Free radicals fulfilling important roles in physiological and pathological conditions, come from both endogenous and exogenous sources. They are the result of cellular processes such as oxygen reduction through the electron transport chain in the mitochondria, but could also be generated in the endoplasmic reticulum, phagocytic cells, peroxisomes, as well as other cell compartments, as a result of central processes such as protein phosphorylation and activation of certain factors specific for transcription, apoptosis, and immunity (168).

When the body's ability to eliminate excessive ROS and/or RNS molecules is exceeded, and they remain in the intercellular space for longer periods of time, oxidation of sensitive biomolecules takes place, such as lipid peroxidation (LPO), essential fatty acid oxidation, or oxidation of guanine DNAbase, causing damage to proper cellular function (169). Among the cellular components involved in regulating OS levels, mitochondria play an important role, dysfunctions at this level having been demonstrated to assist in the pathogenesis of several diseases, including PCOS, metabolic syndrome and diabetes mellitus, cardiovascular disease, and cancer (13, 170, 171). Thus, mitochondrial dysfunction in combination with systemic inflammation is thought to play an essential role in the occurrence of complications associated with metabolic disorders in patients with PCOS, and in the predisposition to cardiovascular disease. In this regard, as a result of mitochondrial dysfunctions, systemic increase of OS occurs in patients of reproductive age who develop symptoms of PCOS, and who have been found to have elevated serum levels of inflammatory markers such as C-reactive protein, interleukins, and proinflammatory cytokines, increased cell counts 
of leukocyte series such as lymphocytes and monocytes, change in tumor necrosis factor (TNF- $\alpha$ ), as well as increases in some metabolites resulting from the processes of carbonylation and oxidation of proteins and lipids (172-174).

Previous studies have revealed that women with PCOS, due to their altered lipid profile, may present certain dysregulated markers, such as increased body mass index, triglycerides, total cholesterol and LDL levels, along with decreased total HDL and HDL2 levels (175-177). In this regard, in PCOS women, several specific metabolites such as nitric oxide (NO) and malondialdehyde (MDA), resulting after lipid metabolization through the reduction of mono- and polyunsaturated fatty acids (MUFAs and PUFAs) and considered oxidative stress markers, have been found at higher levels when compared to control lots (178). On the other hand, Sulaiman et al. have demonstrated the decreased levels of antioxidant molecules glutathione (GSH) and total antioxidant capacity (TAC), capable of cancelling out the destructive impact of free radicals (179). Furthermore, it has been postulated that, especially among women with PCOS, dietary factors may accomplish an important role in promoting the metabolic imbalance (177). For instance, Kazemi et al. have evaluated the relationship between four dietary patterns and the overall ovarian function, and found that the latter was affected by diets that influence obesity, metabolic status and hyperandrogenism regulation (176). The Dietary Approaches to Stop Hypertension (DASH) eating plan has also been previously analyzed by Asemi and colleagues, who highlighted the effect of the DASH diet not only on lipid profiles, but also on oxidative stress markers in PCOS women. They found that women with PCOS undergoing the DASH diet could register significant reduction in insulin, triglyceride and very low-density lipoprotein cholesterol (VLDL-C) values, along with an increased capacity of prooxidant status by elevated levels of total antioxidant capacity (TAC) and GSH (175).

The etiology and circumstances that define the severity of PCOS and the occurrence of risk factors in the development of cardiovascular disease involve the endothelial dysfunction caused by an imbalance between the production and bioavailability of vasoactive molecules that either contract or relax the vessel. Molecules such as endothelium-dependent relaxing factors, endothelium-dependent hyperpolarization factors, endotheliumdependent constricting factors, vasodilator prostaglandins, nitric oxide (NO), fulfill an important role in maintaining a balance for tissue oxygen needs, while also being involved in central processes such as the remodeling of vascular structures by adjusting the vascular tone and diameter to adapt to the metabolic demand in every particular situation $(1,8,180,181)$.

\section{CVD MARKERS IN PCOS}

In light of the absence of conventional CVD risk factors in PCOS women, various studies have focused on the relevance of subclinical CVD markers among these patients. In this regard, CRP and homocysteine have consistently been shown to be increased in the plasma of patients with PCOS. At the same time, emerging microRNA (miRNA) analysis methods have enabled the identification of various dysregulated miRNAs, as a response to metabolic changes characteristic of this condition.

\section{C-Reactive Protein (CRP)}

$\mathrm{CRP}$ is a very common circulating marker, that is usually used as an inflammatory index for individuals. Recent studies have demonstrated the inducing function of CRP in inflammation, as the protein promotes the activation of the complement pathway, induces apoptosis, phagocytosis, and the production of proinflammatory cytokines, such as IL-6 and TNF- $\alpha$ (182). The fact that CRP has been observed to be increased in women with PCOS implicates chronic inflammation as a mechanism that contributes to the increased risk of CVD in women with PCOS (183). A large study performed in 2011 compared CRP levels in the serum of 2.359 women with PCOS with those from 1.289 healthy women, pointing out the significant difference between the two groups, as the group with PCOS had a mean value $95 \%$ higher than the control group (184). These findings were irrespective of the high body mass index (BMI), as they had not changed much after eliminating the bias from BMI.

Different approaches have been indicated to be beneficial for the reduction of CRP in women with PCOS, such as medication with statins or an increase in daily activity. In a study carried out in 2008, which included 40 medication naïve women with PCOS, an effective reduction of mean high sensitivity CRP (hs-CRP) in serum was demonstrated after 12 weeks of atorvastatin administration. This reduction was around $1.5 \mathrm{mg} / \mathrm{liter}$ and was accompanied by a reduction of mean levels of total cholesterol, LDL cholesterol, triglycerides, testosterone, and insulin resistance (185). Moreover, in another study, an increase of 1000 steps per day was associated with a decrease of $13 \%$ in serum CRP levels for a group of 65 women with PCOS, following 6 months of increased daily activity. For this research, data was adjusted for different parameters, such as age and baseline step count, while the observed reduction in CRP levels had a p-value of 0.005 (186).

\section{Homocysteine}

Homocysteine is a well-known marker of oxidative stress, as it has the ability to promote the production of ROS, and, when in high concentration, it can induce the injury of endothelial cells (187). In a big meta-analysis performed in 2013, a group of 4.933 women with PCOS has been compared with a control group of 3.671 healthy women for the detection of circulating markers that indicate OS and PCOS (188). The findings of this study pointed out a $23 \%$ higher mean concentration of homocysteine in the group of women with PCOS, implying the increased levels of OS in this group. Homocysteine can induce OS and increase the risk of CVD in PCOS patients by restricting the expression and the activity of glutathione peroxidase and superoxide dismutase (SOD), while promoting the expression of inducible nitric oxide synthase (iNOS). Moreover, it induces the expression of NADPH oxidase and diminishes thioredoxin, thus favoring the build-up of ROS (189). 
The implication of homocysteine for the development of CVD has been noted since the 1990s, due to the promotion of atherosclerosis and hypercoagulability (190). Apart from PCOS patients, homocysteine has been associated with CVD, such as coronary artery disease (CAD), in individuals with chronic renal dysfunction (191). The fact that atherosclerosis is a pathological process with very strong associations with the onset of CVD, correlates hyperhomocysteinemia with conditions such as stroke, heart failure, and myocardial infarction (192). Moreover, there has been described a strong correlation between homocysteine and CRP expression in vascular smooth muscle cells (VSMCs). In this regard, it has been shown that increased levels of homocysteine can induce the expression of CRP at the transcriptional and the translational level, through harnessing signal pathways of $\mathrm{N}$ methyl-D-aspartate receptor (NMDAr) in VSMCs (193). Therefore, a connection between hyperhomocysteinemia and inflammation comes up, which further corroborates the role of homocysteine in atherosclerosis.

The correlation of homocysteine with CAD has also been pointed out in a study where 70 patients were monitored and compared for their homocysteine serum levels and the presence of CAD through coronary angiography. The patients with CAD had considerably higher levels of homocysteine at a fasting state compared to individuals without $\mathrm{CAD}$, showing increased statistical significance $(\mathrm{p}<0.001)(190)$. In addition, the severity of CAD has been found to be associated with the levels of homocysteine, having a p-value below 0.001 . Homocysteine seems to induce the proliferation of VSMCs while also augmenting the activity of HMG Co-A reductase, which promotes the synthetic production of cholesterol (190). These findings highlight once again the significant role of homocysteine in atherosclerosis.

Over and above, homocysteine has been implicated in the progress of increased arterial stiffness, as it has been correlated with increased aortic stiffness and pulse pressure. Although the mechanism that connects hyperhomocysteinemia with aortic stiffness remains to be further clarified, it seems to be triggered by the elevated oxidation and inflammation levels of vascular endothelial cells, which lack in nitric oxide production and availability (194).

Increased risk of vein thrombosis has been also connected with hyperhomocysteinemia. It has been indicated that elevated levels of homocysteine can enhance platelet adhesion on endothelial cells, while promoting the production of prothrombotic factors, such as tissue plasminogen activator and $\beta$-thromboglobulin $(194,195)$.

\section{MicroRNAs}

MicroRNAs are small non-coding molecules involved in the regulation of numerous genes due to their ability to recognize target sequences situated within the 3 prime untranslated region ( $3^{\prime}$-UTR) of messenger RNA (mRNA). miRNAs have a regulating effect in the post-transcriptional expression of eukaryotic genes and their role in PCOS patients is prominent. In a recent study performed in 2015, where 25 women with PCOS were compared with 24 healthy women of the same age and weight, an increased presence of miRNA-93 and miRNA-
223 has been observed in the group of women with PCOS. The $p$ values for these observations were $<0.01$ and 0.029 respectively, indicating miRNA-93 as a better circulating biomarker for the detection of PCOS (196). The upregulation of miRNA-93 induces insulin resistance, through targeting the CDKN1A and GLUT4 genes, therefore contributing to the increased risk of CVD in PCOS patients (197).

On the other hand, miRNA-223 which targets glucose transporter type 4 (GLUT4), has also been found significantly upregulated in patients with type II diabetes mellitus (T2DM) and left ventricular heart dysfunction (LVD) in biopsies from the left ventricle. When the effect of miRNA-223 was studied in vivo in rat cardiomyocytes, a GLUT4 mediated glucose uptake increase has been found as a response to miRNA-223 upregulation. The regulatory function of miRNA-223 on the post-transcriptional expression of GLUT4 and subsequently on glucose uptake was validated using a synthetic inhibitor of the miRNA in vivo, which diminished the levels of GLUT4 and glucose uptake (198).

Apart from miRNA-93 and miRNA-223, several other miRNAs have been found to be differentially expressed in women with PCOS in the follicular fluid. The most significant ones, which have been observed to demonstrate a more than 2fold change, are miRNA-199b, miRNA-650, miRNA-663b, miRNA-361, miRNA-127, miRNA-382, miRNA-425, miRNA212, miRNA-891b, miRNA-513c, miRNA-507, miRNA-32, miRNA-200c (199).

In a recent meta-analysis performed in 2020, two new miRNAs have been proposed as potential diagnostic biomarkers for PCOS, miR-29a-5p, and miR-320, respectively, indicating miR-29a-5p as a superior potential biomarker (200). Both molecules seem to be downregulated in patients with PCOS. There is a connection between miR-320 and the regulation of genes associated with PCOS morbidity, whereas miR-29a-5p is involved in several metabolic diseases and comorbidities. Moreover, the significant role of miR-29a-5p regarding cell growth, differentiation, and proliferation has also been highlighted. When the DIANA-microT-CDS tool was used for the determination of differentially expressed target genes, which are involved in pathways targeted by miRNAs and associated with PCOS, several results came up. In particular, miR-320 was found to possibly interact with the expression of ESR1, IL-1A, 10, 12B, 37, 8, RAB5B, PDK3, and HMGA2, all of which are involved in estradiol synthesis, steroidogenesis, insulin signaling, fertilization, cell adhesion, and embryo development. On the other hand, miR-29a-5p was found to potentially regulate AR, AKT2, TGF $\beta$, MAP, KFBN3, STARD3, ITGB1, TGFB2, and INRS, which are involved in follicle growth, cell growth, insulin, and collagen synthesis (200).

Nowadays, the correlation between miRNAs and different pathological conditions has been profoundly studied, connecting the dysregulated expression of miRNAs with complex diseases, including CVD. Usually, the targets of a miRNA expand on several different mRNAs, thus affecting the expression of a collection of genes. It has been estimated that around 30\% of genes are regulated by miRNAs (201), depicting their significance in human physiology. A promising field for future 
research is the monitoring of serum miRNAs, so as to be used as diagnostic, prognostic, or treatment response markers.

\section{CONCLUSION}

Polycystic ovary syndrome is one of the most common endocrine disorders in women of childbearing age and the most common source of anovulatory infertility. This syndrome presents heterogeneous clinical variants, where the pathogenesis involves the existence of several cardiometabolic abnormalities that manifest through changes in the metabolic balance in which mitochondrial dysfunctions play a key role in the progression and occurrence of complications. Besides mitochondrial dysfunction, systemic inflammation characteristic of PCOS women also fulfills an important role in the occurrence of complications associated with metabolic disorders in these patients, as well as in the predisposition to cardiovascular disease.

Among the metabolic disorders associated with PCOS that occur from adolescence, insulin resistance and impaired glucose tolerance are included, as well as other manifestations that are more prominently expressed with age, such as hyperglycemia, obesity - especially visceral, hepatic steatosis, dyslipidemia, hypertension, type II diabetes, and an increased risk of cardiovascular diseases such as hypertension and myocardial infarction. Moreover, in addition to other features such as chronic low-grade inflammatory state and endothelial dysfunction, PCOS poses an increased risk of developing cardiovascular disorders. One of the diverse mechanisms that could enhance the overall cardiovascular risk especially by causing arterial hypertension is represented by endothelial dysfunction, which is tightly correlated with ROS levels that are highly dependent upon the oxidative stress in the body.

\section{REFERENCES}

1. Senoner T, Dichtl W. Oxidative Stress in Cardiovascular Diseases: Still a Therapeutic Target? Nutrients (2019) 11:2090. doi: 10.3390/nu11092090

2. Finkel T. Signal transduction by reactive oxygen species. J Cell Biol (2011) 194:7-15. doi: 10.1083/jcb.201102095

3. Tsutsui H, Kinugawa S, Matsushima S. Oxidative stress and heart failure. Am J Physiol Heart Circ Physiol (2011) 301:H2181-90. doi: 10.1152/ ajpheart.00554.2011

4. Samman Tahhan A, Sandesara PB, Hayek SS, Alkhoder A, Chivukula K, Hammadah $\mathrm{M}$, et al. Association between oxidative stress and atrial fibrillation. Heart Rhythm (2017) 14:1849-55. doi: 10.1016/j.hrthm.2017.07.028

5. Baradaran A, Nasri H, Rafieian-Kopaei M. Oxidative stress and hypertension: Possibility of hypertension therapy with antioxidants. $J$ Res Med Sci (2014) 19:358-67.

6. Kattoor AJ, Pothineni NVK, Palagiri D, Mehta JL. Oxidative Stress in Atherosclerosis. Curr Atheroscl Rep (2017) 19:42. doi: 10.1007/s11883-0170678-6

7. Ashok V, Ranganathan R, Chander S, Damodar S, Bhat S, Nataraj KS, et al. Comparison of Diagnostic Yield of a FISH Panel Against Conventional Cytogenetic Studies for Hematological Malignancies: A South Indian Referral Laboratory Analysis Of 201 Cases. Asian Pacific J Cancer Prev APJCP (2017) 18:3457-64. doi: 10.22034/APJCP.2017.18.12.3457

8. Godo S, Shimokawa H. Endothelial Functions. Arterioscler Thromb Vasc Biol (2017) 37:e108-14. doi: 10.1161/atvbaha.117.309813
In this respect, high ROS levels are further involved in genetic changes such as point mutations, DNA strand breaks, aberrant DNA cross-linking, and DNA-protein cross-linking, DNA methylation, with the effect of silencing the genes tumor suppressors, phenomena that were observed in women with PCOS syndrome. Moreover, owing to OS's ability to induce DNA injury and methylation, the activation of oncogenes along with antioncogene silencing are not out of the question among these patients, which are, in fact, also susceptible to developing endometrial cancer.

Overall, current literature suggests an evident increase in OS among PCOS women, contributing to the numerous metabolic and cardiovascular dysfunctions characteristic of this disease. The development of both preventive and therapeutic strategies aimed at the cardiovascular risk of these patients ought to therefore involve further studies regarding the reduction of oxidative stress.

\section{AUTHOR CONTRIBUTIONS}

Conceptualization, FD, AB, CD, PA. Methodology, SC, VV. Investigation, SO, DC. Writing-original draft preparation, FD, $\mathrm{CD}, \mathrm{AB}, \mathrm{PA}, \mathrm{CC}$. Writing-review and editing CC, SO. Supervision, DC. Funding acquisition, NS, SC. All authors contributed to the article and approved the submitted version.

\section{FUNDING}

This work was supported by grants of the Romanian Ministry of Research and Innovation, CCCDI-UEFISCDI, project number PN-III-P1-1.2-PCCDI-2017-0833/68/2018.

9. Çetin M, Tunçdemir P, Karaman K, Yel S, Karaman E, Özgökçe M et al. Cardiovascular evaluation and serum paraoxonase-1 levels in adolescents with polycystic ovary syndrome. J Obstetr Gynaecol (2020) 40:90-5. doi: 10.1080/01443615.2019.1604643

10. Osibogun O, Ogunmoroti O, Michos E. Polycystic Ovary Syndrome and Cardiometabolic Risk: Opportunities for Cardiovascular Disease Prevention. Trends Cardiovasc Med (2019) 30(7):399-404. doi: 10.1016/j.tcm.2019.08.010

11. McCartney CR, Campbell RE. Abnormal GnRH Pulsatility in Polycystic Ovary Syndrome: Recent Insights. Curr Opin Endocr Metab Res (2020) 12:78-84. doi: 10.1016/j.coemr.2020.04.005

12. Ho CH, Chang CM, Li HY, Shen HY, Lieu FK, Wang PS. Dysregulated immunological and metabolic functions discovered by a polygenic integrative analysis for PCOS. Reprod Biomed Online (2020) 40:160-7. doi: 10.1016/j.rbmo.2019.09.011

13. Zhang J, Bao Y, Zhou X, Zheng L. Polycystic ovary syndrome and mitochondrial dysfunction. Reprod Biol Endocrinol (2019) 17:67. doi: 10.1186/s12958-019-0509-4

14. Yildiz BO. Diagnosis of hyperandrogenism: clinical criteria. Best Pract Res Clin Endocrinol Metab (2006) 20:167-76. doi: 10.1016/j.beem.2006.02.004

15. Escobar-Morreale HF, San Millán JL. Abdominal adiposity and the polycystic ovary syndrome. Trends Endocrinol Metabol: TEM (2007) 18:266-72. doi: 10.1016/j.tem.2007.07.003

16. Vázquez-Vela ME, Torres N, Tovar AR. White adipose tissue as endocrine organ and its role in obesity. Arch Med Res (2008) 39:715-28. doi: 10.1016/ j.arcmed.2008.09.005 
17. Spritzer P, Lecke S, Satler F, Morsch D. Adipose tissue dysfunction, adipokines and low-grade chronic inflammation in PCOS. Reprod (Cambridge England) (2015) 149(5):R219-27. doi: 10.1530/REP-14-0435

18. Ziech D, Franco R, Pappa A, Panayiotidis MI. Reactive oxygen species (ROS)-induced genetic and epigenetic alterations in human carcinogenesis. Mutat Res (2011) 711:167-73. doi: 10.1016/j.mrfmmm.2011.02.015

19. Lebedeva MA, Eaton JS, Shadel GS. Loss of p53 causes mitochondrial DNA depletion and altered mitochondrial reactive oxygen species homeostasis. Biochim Biophys Acta (2009) 1787:328-34. doi: 10.1016/j.bbabio.2009.01.004

20. Donkena KV, Young CY, Tindall DJ. Oxidative stress and DNA methylation in prostate cancer. Obstetr Gynecol Int (2010) 2010:302051. doi: 10.1155/ 2010/302051

21. Franco R, Schoneveld O, Georgakilas AG, Panayiotidis MI. Oxidative stress, DNA methylation and carcinogenesis. Cancer Lett (2008) 266:6-11. doi: 10.1016/j.canlet.2008.02.026

22. Bartsch H, Nair J. Chronic inflammation and oxidative stress in the genesis and perpetuation of cancer: Role of lipid peroxidation, DNA damage, and repair. Langenbeck's Arch Surg Deutsche Gesellschaft Für Chirurgie (2006) 391:499-510. doi: 10.1007/s00423-006-0073-1

23. Goodarzi MO, Dumesic DA, Chazenbalk G, Azziz R. Polycystic ovary syndrome: etiology, pathogenesis and diagnosis. Nat Rev Endocrinol (2011) 7:219-31. doi: 10.1038/nrendo.2010.217

24. McCartney CR, Marshall JC. CLINICAL PRACTICE. Polycystic Ovary Syndrome. N Engl J Med (2016) 375:54-64. doi: 10.1056/NEJMcp1514916

25. Barthelmess EK, Naz RK. Polycystic ovary syndrome: current status and future perspective. Front Biosci (Elite Ed) (2014) 6:104-19. doi: 10.2741/e695

26. Witchel SF, Oberfield S, Rosenfield RL, Codner E, Bonny A, Ibáñez L, et al. The Diagnosis of Polycystic Ovary Syndrome during Adolescence. Hormone Res Paediatr (2015) 83:376-89. doi: 10.1159/000375530

27. Strauss JF3rd. Some new thoughts on the pathophysiology and genetics of polycystic ovary syndrome. Ann New Y Acad Sci (2003) 997:42-8. doi: 10.1196/annals.1290.005

28. Witchel SF, Oberfield SE, Peña AS. Polycystic Ovary Syndrome: Pathophysiology, Presentation, and Treatment With Emphasis on Adolescent Girls. J Endocr Soc (2019) 3:1545-73. doi: 10.1210/js.2019-00078

29. Bednarska S, Siejka A. The pathogenesis and treatment of polycystic ovary syndrome: What's new? Adv Clin Exp Med (2017) 26:359-67. doi: 10.17219/ acem $/ 59380$

30. Mihailidis J, Dermesropian R, Taxel P, Luthra P, Grant-Kels JM. Endocrine evaluation of hirsutism. Int J Women's Dermatol (2017) 3:S6-S10. doi: 10.1016/j.ijwd.2017.02.007

31. Binita G, Suprava P, Mainak C, Koner BC, Alpana S. Correlation of prolactin and thyroid hormone concentration with menstrual patterns in infertile women. J Reprod Infertil (2009) 10:207-12. doi: 10.18203/23201770.ijrcog20170400

32. Dumesic DA, Oberfield SE, Stener-Victorin E, Marshall JC, Laven JS, Legro RS. Scientific Statement on the Diagnostic Criteria, Epidemiology, Pathophysiology, and Molecular Genetics of Polycystic Ovary Syndrome. Endocrine Rev (2015) 36:487-525. doi: 10.1210/er.2015-1018

33. Rojas J, Chávez M, Olivar L, Rojas M, Morillo J, Mejías J, et al. Polycystic Ovary Syndrome, Insulin Resistance, and Obesity: Navigating the Pathophysiologic Labyrinth. Int J Reprod Med (2014) 2014:719050. doi: 10.1155/2014/719050

34. Shaaban Z, Khoradmehr A, Jafarzadeh Shirazi MR, Tamadon A. Pathophysiological mechanisms of gonadotropins- and steroid hormonesrelated genes in etiology of polycystic ovary syndrome. Iran J Basic Med Sci (2019) 22:3-16. doi: 10.22038/ijbms.2018.31776.7646

35. Fenichel P, Rougier C, Hieronimus S, Chevalier N. Which origin for polycystic ovaries syndrome: Genetic, environmental or both? Annales D'endocrinol (2017) 78:176-85. doi: 10.1016/j.ando.2017.04.024

36. Hoffman B, Schorge J, Schaffer J, Halvorson L, Bradshaw K, Cunningham F. Williams Gynecology. 2nd ed. New York: Mcgraw-hill (2012).

37. Cheung AP, Cog F. Polycystic ovary syndrome: a contemporary view. J Obstetr Gynaecol Canada JOGC J D'obstetr Gynecol Du Canada JOGC (2010) 32:423-5. doi: 10.1016/s1701-2163(16)34493-0

38. Zheng L, Annab LA, Afshari CA, Lee WH, Boyer TG. BRCA1 mediates ligand-independent transcriptional repression of the estrogen receptor. Proc Natl Acad Sci USA (2001) 98:9587-92. doi: 10.1073/pnas.171174298
39. Chung TK, Lau TS, Cheung TH, Yim SF, Lo KW, Siu NS, et al. Dysregulation of microRNA-204 mediates migration and invasion of endometrial cancer by regulating FOXC1. Int J Cancer (2012) 130:1036-45. doi: 10.1002/ ijc. 26060

40. Moore AM, Campbell RE. The neuroendocrine genesis of polycystic ovary syndrome: A role for arcuate nucleus GABA neurons. J Steroid Biochem Mol Biol (2016) 160:106-17. doi: 10.1016/j.jsbmb.2015.10.002

41. Sliwowska JH, Fergani C, Gawałek M, Skowronska B, Fichna P, Lehman MN. Insulin: its role in the central control of reproduction. Physiol Behav (2014) 133:197-206. doi: 10.1016/j.physbeh.2014.05.021

42. Roland AV, Moenter SM. Reproductive neuroendocrine dysfunction in polycystic ovary syndrome: insight from animal models. Front Neuroendocrinol (2014) 35:494-511. doi: 10.1016/j.yfrne.2014.04.002

43. Ubuka T, Morgan K, Pawson AJ, Osugi T, Chowdhury VS, Minakata H, et al. Identification of human GnIH homologs, RFRP-1 and RFRP-3, and the cognate receptor, GPR147 in the human hypothalamic pituitary axis. PLoS One (2009) 4:e8400. doi: 10.1371/journal.pone.0008400

44. Catteau-Jonard S, Dewailly D. Pathophysiology of Polycystic Ovary Syndrome: The Role of Hyperandrogenism. Front Horm Res (2013) 40:22-7. doi: 10.1159/000341679

45. Mehrabian F, Afghahi M. Can Sex-hormone Binding Globulin Considered as a Predictor of Response to Pharmacological Treatment in Women with Polycystic Ovary Syndrome? Int J Prev Med (2013) 4:1169-74.

46. Lerchbaum E, Schwetz V, Rabe T, Giuliani A, Obermayer-Pietsch B. Hyperandrogenemia in polycystic ovary syndrome: exploration of the role of free testosterone and androstenedione in metabolic phenotype. PLoS One (2014) 9:e108263-e108263. doi: 10.1371/journal.pone.0108263

47. Filippou P, Homburg R. Is foetal hyperexposure to androgens a cause of PCOS? Hum Reprod Update (2017) 23:421-32. doi: 10.1093/humupd/ $\mathrm{dmx} 013$

48. Howland MA, Sandman CA, Glynn LM. Developmental origins of the human hypothalamic-pituitary-adrenal axis. Expert Rev Endocrinol Metab (2017) 12:321-39. doi: 10.1080/17446651.2017.1356222

49. Puttabyatappa M, Cardoso RC, Padmanabhan V. Effect of maternal PCOS and PCOS-like phenotype on the offspring's health. Mol Cell Endocrinol (2016) 435:29-39. doi: 10.1016/j.mce.2015.11.030

50. Gourgari E, Lodish M, Keil M, Sinaii N, Turkbey E, Lyssikatos C, et al. Bilateral Adrenal Hyperplasia as a Possible Mechanism for Hyperandrogenism in Women With Polycystic Ovary Syndrome. J Clin Endocrinol Metab (2016) 101:3353-60. doi: 10.1210/jc.2015-4019

51. De Leo V, Musacchio MC, Cappelli V, Massaro MG, Morgante G, Petraglia F. Genetic, hormonal and metabolic aspects of PCOS: an update. Reprod Biol Endocrinol (2016) 14:38-8. doi: 10.1186/s12958-016-0173-x

52. Rosenfield RL, Ehrmann DA. The Pathogenesis of Polycystic Ovary Syndrome (PCOS): The Hypothesis of PCOS as Functional Ovarian Hyperandrogenism Revisited. Endocrine Rev (2016) 37:467-520. doi: 10.1210/er.2015-1104

53. Deligeoroglou E, Kouskouti C, Christopoulos P. The role of genes in the polycystic ovary syndrome: predisposition and mechanisms. Gynecolog Endocrinol (2009) 25:603-9. doi: 10.1080/09513590903015619

54. Stocco C. Tissue physiology and pathology of aromatase. Steroids (2012) 77:27-35. doi: 10.1016/j.steroids.2011.10.013

55. Spritzer PM, Lecke SB, Satler F, Morsch DM. Adipose tissue dysfunction, adipokines, and low-grade chronic inflammation in polycystic ovary syndrome. Reproduction (2015) 149:R219. doi: 10.1530/rep-14-0435

56. Wilcox G. Insulin and insulin resistance. Clin Biochem Rev (2005) 26:19-39.

57. Burcelin R, Thorens B, Glauser M, Gaillard R, Pralong F. GonadotropinReleasing Hormone Secretion from Hypothalamic Neurons: Stimulation by Insulin and Potentiation by Leptin. Endocrinology (2003) 144:4484-91. doi: 10.1210/en.2003-0457

58. Marshall JC, Dunaif A. Should all women with PCOS be treated for insulin resistance? Fertil Steril (2012) 97:18-22. doi: 10.1016/j.fertnstert.2011.11.036

59. Toprak S, Yönem A, Cakir B, Güler S, Azal O, Ozata M, et al. Insulin resistance in nonobese patients with polycystic ovary syndrome. Hormone Res (2001) 55:65-70. doi: 10.1159/000049972

60. Ashraf S, Nabi M, Rasool S, Rashid F, Amin ,S. Hyperandrogenism in polycystic ovarian syndrome and role of CYP gene variants: a review. Egyptian J Med Hum Genet (2019) 20:25. doi: 10.1186/s43042-019-0031-4 
61. Srimyooran Branavan U, Nv C, Wss W, Wijeyaratne C. Polycystic Ovary Syndrome: Genetic Contributions from the Hypothalamic-PituitaryGonadal Axis. Int Arch Endocrinol Clin Res (2018) 4:013. doi: 10.23937/ 2572-407X.1510013

62. Ruddenklau A, Campbell RE. Neuroendocrine Impairments of Polycystic Ovary Syndrome. Endocrinology (2019) 160:2230-42. doi: 10.1210/en.2019-00428

63. Cornier M-A, Dabelea D, Hernandez TL, Lindstrom RC, Steig AJ, Stob NR, et al. The metabolic syndrome. Endocrine Rev (2008) 29:777-822. doi: 10.1210/er.2008-0024

64. Geffner ME, Golde DW. Selective insulin action on skin, ovary, and heart in insulin-resistant states. Diabetes Care (1988) 11:500-5. doi: 10.2337/ diacare.11.6.500

65. Wu S, Divall S, Wondisford F, Wolfe A. Reproductive Tissues Maintain Insulin Sensitivity in Diet-Induced Obesity. Diabetes (2012) 61:114-23. doi: $10.2337 / \mathrm{db} 11-0956$

66. Richards JS, Ren YA, Candelaria N, Adams JE, Rajkovic A. Ovarian Follicular Theca Cell Recruitment, Differentiation, and Impact on Fertility: 2017 Update. Endocrine Rev (2018) 39:1-20. doi: 10.1210/er.2017-00164

67. Lindheim SR, Glenn TL, Smith MC, Gagneux P. Ovulation Induction for the General Gynecologist. J Obstet Gynaecol India (2018) 68:242-52. doi: $10.1007 / \mathrm{s} 13224-018-1130-8$

68. Franks S, Stark J, Hardy K. Follicle dynamics and anovulation in polycystic ovary syndrome. Hum Reprod Update (2008) 14:367-78. doi: 10.1093/ humupd/dmn015

69. Park JC, Lim SY, Jang TK, Bae JG, Kim JI, Rhee JH. Endometrial histology and predictable clinical factors for endometrial disease in women with polycystic ovary syndrome. Clin Exp Reprod Med (2011) 38:42-6. doi: $10.5653 / \mathrm{cerm} .2011 .38 .1 .42$

70. Monniaux D, Cadoret V, Clément F, Dalbies-Tran R, Elis S, Fabre S, et al. "Folliculogenesis". In: I Huhtaniemi and L Martini, editors. Encyclopedia of Endocrine Diseases, 2nd ed. Oxford: Academic Press (2019). p. 377-98. doi: 10.1016/B978-0-12-801238-3.64550-6pp

71. Kumar P, Sait SF. Luteinizing hormone and its dilemma in ovulation induction. J Hum Reprod Sci (2011) 4:2-7. doi: 10.4103/0974-1208.82351

72. Lopez H, Sartori R, Wiltbank MC. Reproductive Hormones and Follicular Growth During Development of One or Multiple Dominant Follicles in Cattle1. Biol Reprod (2005) 72:788-95. doi: 10.1095/biolreprod.104. 035493

73. Jonard S, Dewailly D. The follicular excess in polycystic ovaries, due to intraovarian hyperandrogenism, may be the main culprit for the follicular arrest. Hum Reprod Update (2004) 10:107-17. doi: 10.1093/humupd/dmh010

74. Dumesic DA, Lesnick TG, Stassart JP, Ball GD, Wong A, Abbott DH. Intrafollicular antimüllerian hormone levels predict follicle responsiveness to follicle-stimulating hormone (FSH) in normoandrogenic ovulatory women undergoing gonadotropin releasing-hormone analog/recombinant human FSH therapy for in vitro fertilization and embryo transfer. Fertil Steril (2009) 92:217-21. doi: 10.1016/j.fertnstert.2008.04.047

75. Diamanti-Kandarakis E. Polycystic ovarian syndrome: pathophysiology, molecular aspects and clinical implications. Expert Rev Mol Med (2008) 10:e3. doi: $10.1017 / \mathrm{s} 1462399408000598$

76. Dupont J, Scaramuzzi RJ. Insulin signalling and glucose transport in the ovary and ovarian function during the ovarian cycle. Biochem J (2016) 473:1483-501. doi: 10.1042/BCJ20160124

77. Welt CK, Taylor AE, Fox J, Messerlian GM, Adams JM, Schneyer AL. Follicular Arrest in Polycystic Ovary Syndrome Is Associated with Deficient Inhibin A and B Biosynthesis. J Clin Endocrinol Metab (2005) 90:5582-7. doi: 10.1210/jc.2005-0695

78. Webber LJ, Stubbs S, Stark J, Trew GH, Margara R, Hardy K, et al. Formation and early development of follicles in the polycystic ovary. Lancet (London England) (2003) 362:1017-21. doi: 10.1016/s0140-6736 (03)14410-8

79. Jonard S, Dewailly D. The follicular excess in polycystic ovaries, due to intraovarian hyperandrogenism, may be the main culprit for the follicular arrest. Hum Reprod Update (2004) 10:107-17. doi: 10.1093/humupd/dmh010

80. Johansson J, Stener-Victorin E. Polycystic ovary syndrome: effect and mechanisms of acupuncture for ovulation induction. Evid Based Complement Alternat Med (2013) 2013:762615-5. doi: 10.1155/2013/ 762615
81. Tsutsumi R, Webster NJG. GnRH pulsatility, the pituitary response and reproductive dysfunction. Endocr J (2009) 56:729-37. doi: 10.1507/ endocrj.k09e-185

82. Lashen $\mathrm{H}$. Role of metformin in the management of polycystic ovary syndrome. Ther Adv Endocrinol Metab (2010) 1:117-28. doi: 10.1177/ 2042018810380215

83. Johnson NP. Metformin use in women with polycystic ovary syndrome. Ann Trans Med (2014) 2:56-6. doi: 10.3978/j.issn.2305-5839.2014.04.15

84. Duleba AJ, Dokras A. Is PCOS an inflammatory process? Fertil Steril (2012) 97:7-12. doi: 10.1016/j.fertnstert.2011.11.023

85. Wild RA, Carmina E, Diamanti-Kandarakis E, Dokras A, Escobar-Morreale HF, Futterweit W, et al. Assessment of cardiovascular risk and prevention of cardiovascular disease in women with the polycystic ovary syndrome: a consensus statement by the Androgen Excess and Polycystic Ovary Syndrome (AE-PCOS) Society. J Clin Endocrinol Metab (2010) 95:203849. doi: 10.1210/jc.2009-2724

86. Hulsmans M, Holvoet P. The vicious circle between oxidative stress and inflammation in atherosclerosis. J Cell Mol Med (2010) 14:70-8. doi: 10.1111/j.1582-4934.2009.00978.x

87. Garcia M, Mulvagh SL, Merz CNB, Buring JE, Manson JE. Cardiovascular Disease in Women: Clinical Perspectives. Circ Res (2016) 118:1273-93. doi: 10.1161/CIRCRESAHA.116.307547

88. Pathak E. Is Heart Disease or Cancer the Leading Cause of Death in United States Women? Women Health Issues (2016) 26(6):589-94. doi: 10.1016/ j.whi.2016.08.002

89. Abuful A, Gidron Y, Henkin Y. Physicians' attitudes toward preventive therapy for coronary artery disease: is there a gender bias? Clin Cardiol (2005) 28:389-93. doi: 10.1002/clc.4960280809

90. Chou AF, Scholle SH, Weisman CS, Bierman AS, Correa-de-Araujo R, Mosca L. Gender disparities in the quality of cardiovascular disease care in private managed care plans. Women's Health Issues Off Publ Jacobs Institute Women's Health (2007) 17:120-30. doi: 10.1016/j.whi.2007.03.002

91. Gu Q, Burt VL, Paulose-Ram R, Dillon CF. Gender differences in hypertension treatment, drug utilization patterns, and blood pressure control among US adults with hypertension: data from the National Health and Nutrition Examination Survey 1999-2004. Am J Hypertension (2008) 21:789-98. doi: 10.1038/ajh.2008.185

92. Mosca L, Benjamin EJ, Berra K, Bezanson JL, Dolor RJ, Lloyd-Jones DM, et al. Effectiveness-based guidelines for the prevention of cardiovascular disease in women-2011 update: a guideline from the american heart association. Circulation (2011) 123:1243-62. doi: 10.1161/CIR.0b013e 31820faaf8

93. Keteepe-Arachi T, Sharma S. Cardiovascular Disease in Women: Understanding Symptoms and Risk Factors. Eur Cardiol (2017) 12:10-3. doi: 10.15420/ecr.2016:32:1

94. Pinola P, Puukka K, Piltonen TT, Puurunen J, Vanky E, SundströmPoromaa I, et al. Normo- and hyperandrogenic women with polycystic ovary syndrome exhibit an adverse metabolic profile through life. Fertil Steril (2017) 107(3):788-95.e782. doi: 10.1016/j.fertnstert.2016.12.017

95. Schmidt J, Landin-Wilhelmsen K, Brannstrom M, Dahlgren E. Cardiovascular disease and risk factors in PCOS women of postmenopausal age: a 21-year controlled follow-up study. J Clin Endocrinol Metab (2011) 96 (12):3794-803. doi: 10.1210/jc.2011-1677

96. Brown ZA, Louwers YV, Fong SL, Valkenburg O, Birnie E, de Jong FH, et al. The phenotype of polycystic ovary syndrome ameliorates with aging. Fertil Steril (2011) 96(5):1259-65. doi: 10.1016/j.fertnstert.2011.09.002

97. Meun C, Franco OH, Dhana K, Jaspers L, Muka T, Louwers Y, et al. High Androgens in Postmenopausal Women and the Risk for Atherosclerosis and Cardiovascular Disease: The Rotterdam Study. J Clin Endocrinol Metab (2018) 103(4):1622-30. doi: 10.1210/jc.2017-02421

98. Zhao Y, Qiao J. Ethnic differences in the phenotypic expression of polycystic ovary syndrome. Steroids (2013) 78(8):755-60. doi: 10.1016/j.steroids.2013. 04.006

99. Fauser BC, Tarlatzis BC, Rebar RW, Legro RS, Balen AH, Lobo R, et al. Consensus on women's health aspects of polycystic ovary syndrome (PCOS): the Amsterdam ESHRE/ASRM-Sponsored 3rd PCOS Consensus Workshop. Group Fertil Steril (2012) 97(1):28-38.e25. doi: 10.1016/j.fertnstert.2011. 09.024 
100. Wild RA. Polycystic ovary syndrome: a risk for coronary artery disease? Am J Obstetr Gynecol (2002) 186:35-43. doi: 10.1067/mob.2002.119180

101. Chiu WL, Boyle J, Vincent A, Teede H, Moran LJ. Cardiometabolic Risks in Polycystic Ovary Syndrome: Non-Traditional Risk Factors and the Impact of Obesity. Neuroendocrinology (2017) 104:412-24. doi: 10.1159/000455233

102. Palomba S, Santagni S, Falbo A, La Sala GB. Complications and challenges associated with polycystic ovary syndrome: current perspectives. Int $J$ Womens Health (2015) 7:745-63. doi: 10.2147/IJWH.S70314

103. Fauser BC, Tarlatzis BC, Rebar RW, Legro RS, Balen AH, Lobo R, et al. Consensus on women's health aspects of polycystic ovary syndrome (PCOS): the Amsterdam ESHRE/ASRM-Sponsored 3rd PCOS Consensus Workshop Group. Fertil Steril (2012) 97:28-38.e25. doi: 10.1016/j.fertnstert.2011.09.024

104. Bentley-Lewis R, Seely E, Dunaif A. Ovarian hypertension: polycystic ovary syndrome. Endocrinol Metab Clin North Am (2011) 40(2):433-x. doi: 10.1016/j.ecl.2011.01.009

105. Orbetzova MM, Shigarminova RG, Genchev GG, Milcheva BA, Lozanov LB, Genov NS, et al. Role of 24-hour monitoring in assessing blood pressure changes in polycystic ovary syndrome. Folia Med (Plovdiv) (2003) 45(3):21-5.

106. Wild S, Pierpoint T, Jacobs H, McKeigue P. Long-term consequences of polycystic ovary syndrome: results of a 31 year follow-up study. Hum Fertil (Camb) (2000) 3(2):101-5. doi: 10.1080/1464727002000198781

107. Holte J, Gennarelli G, Berne C, Bergh T, Lithell H. Elevated ambulatory daytime blood pressure in women with polycystic ovary syndrome: a sign of a pre-hypertensive state? Hum Reprod (1996) 11(1):23-8. doi: 10.1093/ oxfordjournals.humrep.a019028

108. Elting MW, Korsen TJ, Bezemer PD, Schoemaker J. Prevalence of diabetes mellitus, hypertension and cardiac complaints in a follow-up study of a Dutch PCOS population. Hum Reprod (2001) 16(3):556-60. doi: 10.1093/ humrep/16.3.556

109. Vrbíková J, Cífková R, Jirkovská $\mathrm{A}$, Lánská $\mathrm{V}$, Platilová $\mathrm{H}$, Zamrazil V, et al. Cardiovascular risk factors in young Czech females with polycystic ovary syndrome. Hum Reprod (2003) 18(5):980-4. doi: 10.1093/humrep/deg218

110. Talbott E, Clerici A, Berga SL, Kuller L, Guzick D, Detre K, et al. Adverse lipid and coronary heart disease risk profiles in young women with polycystic ovary syndrome: results of a case-control study. J Clin Epidemiol (1998) 51 (5):415-22. doi: 10.1016/S0895-4356(98)00010-9

111. Conway GS, Agrawal R, Betteridge DJ, Jacobs HS. Risk factors for coronary artery disease in lean and obese women with the polycystic ovary syndrome. ClinEndocrinol (Oxf) (1992) 37(2):119-25. doi: 10.1111/j.1365-2265.1992. tb02295.x

112. Amiri M, Ramezani Tehrani F, Behboudi-Gandevani S, Bidhendi-Yarandi R, Carmina E. Risk of hypertension in women with polycystic ovary syndrome: a systematic review, meta-analysis and meta-regression. Reprod Biol Endocrinol (2020) 18(1):23. doi: 10.1186/s12958-020-00576-1

113. Sam S. Obesity and Polycystic Ovary Syndrome. Obes Manag (2007) 3(2):6973. doi: $10.1089 /$ obe. 2007.0019

114. Lim SS, Davies MJ, Norman RJ, Moran LJ. Overweight, obesity and central obesity in women with polycystic ovary syndrome: a systematic review and meta-analysis. Hum Reprod Update (2012) 18(6):618-37. doi: 10.1093/ humupd/dms030

115. Rachon D, Teede H. Ovarian function and obesity-interrelationship, impact on women's reproductive lifespan and treatment options. Molec Cell Endocrinol (2010) 316(2):172-9. doi: 10.1016/j.mce.2009.09.026

116. Yildirir A, Aybar F, Kabakci G, Yarali H, Oto A. Heart rate variability in young women with polycystic ovary syndrome. Ann Noninvasive Electrocardiol (2006) 11(4):306-12. doi: 10.1111/j.1542-474X.2006.00122.x

117. Muller-Wieland D, Kotzka J, Knebel B, Krone W. Metabolic syndrome and hypertension: pathophysiology and molecular basis of insulin resistance. Basic Res Cardiol (1998) 93(Suppl 2):131-4. doi: 10.1007/s003950050238

118. Muniyappa R, Montagnani M, Koh KK, Quon MJ. Cardiovascular actions of insulin. Endocr Rev (2007) 28(5):463-91. doi: 10.1210/er.2007-0006

119. Barnes RB, Namnoum AB, Rosenfield RL, Layman LC. The role of LH and FSH in ovarian androgen secretion and ovarian follicular development: Clinical studies in a patient with isolated FSH deficiency and multicystic ovaries: Case report. Hum Reprod (2002) 17:88-91. doi: 10.1093/humrep/ 17.1.88

120. Burt Solorzano CM, McCartney CR, Blank SK, Knudsen KL, Marshall JC. Hyperandrogenaemia in adolescent girls: origins of abnormal gonadotropin- releasing hormone secretion. BJOG Int J Obstetr Gynaecol (2010) 117:143-9. doi: 10.1111/j.1471-0528.2009.02383.x

121. Jaliseh HK, Tehrani FR, Behboudi-Gandevani S, Hosseinpanah F, Khalili D, Cheraghi L, et al. Polycystic ovary syndrome is a risk factor for diabetes and prediabetes in middle-aged but not elderly women: a long-term populationbased follow-up study. Fertil Steril (2017) 108(6):1078-84. doi: 10.1016/ j.fertnstert.2017.09.004

122. Joham AE, Boyle JA, Zoungas S, Teede HJ. Hypertension in reproductive aged women with polycystic ovary syndrome and association with obesity. Am J Hypertens (2014) 28(7):847-51. doi: 10.1093/ajh/hpu251

123. Winters SJ, Talbott E, Guzick DS, Zborowski J, McHugh KP. Serum testosterone levels decrease in middle age in women with the polycystic ovary syndrome. Fertil Steril (2000) 73:724-9. doi: 10.1016/s0015-0282(99) 00641-x

124. Carmina E. Cardiovascular risk and events in polycystic ovary syndrome. Climacteric (2009) 12(sup1):22-5. doi: 10.1080/13697130903003842

125. Carmina E, Campagna A, Lobo R. Emergence of ovulatory cycles with aging in women with polycystic ovary syndrome (PCOS) alters the trajectory of cardiovascular and metabolic risk factors. Hum Reprod (2013) 28(8):224552. doi: 10.1093/humrep/det119

126. Lo JC, Feigenbaum SL, Yang J, Pressman AR, Selb JV, Go AS. Epidemiology and adverse cardiovascular risk profile of diagnosed polycystic ovary syndrome. J Clin Endocrinol Metab (2006) 91(4):1357-63. doi: 10.1210/ jc.2005-2430

127. Westerveld HE, Hoogendoon M, de Jong AWF, Goverde AJ, Fauser BCJM, Dallinga-Thie GM. Cadiometabolic abnormalities in the polycystic ovary syndrome: pharmacotherapeutic insights. Pharmacol Ther (2008) 1 19:22341. doi: 10.1016/j.pharmthera.2008.04.009

128. Diamanti-Kandarakis E, Kandaraki E, Christakou C, Panidis D. The effect of pharmaceutical intervention on lipid profile in polycystic ovary sydrome. Obes Rev (2009) 10:431-41. doi: 10.1111/j.1467-789X.2009.00588.x

129. Dokras A, Jagasia DH, Maifeld M, Sinkey CA, VanVoorhis BJ, Haynes WG. Obesity/insulin resistance but not hyperandrogenism is an important mediator of vascular dysfunction in women with PCOS. Fertil Steril (2006) 86:1702-9. doi: 10.1016/j.fertnstert.2006.05.038

130. Talbott EO, Zborowski J, Rager J, Stragand JR. Is there an independent effect of polycystic ovary syndrome (PCOS) and menopause on the prevalence of subclinical atherosclerosis in middle aged women. Vasc Halth Risk Manage (2008) 4(2):453-62. doi: 10.2147/VHRM.S1452

131. Talbott EO, Guzick DS, Sutton-Tyrell, McHugh-Pemu KP, Zborowski JV, Remsberg KE, et al. Evidence for association between polycysic ovary syndrome and premature carotid atherosclerosis in middle-aged women. Arterioscler Thromb Vasc Biol (2000) 20:2414-21. doi: 10.1161/01.ATV.20. 11.2414

132. Solomon CG, Hu FB, Dunaif A, Rich-Edwards JE, Stampfer MJ, Willett WC, et al. Menstrual cycle irregularity and the risk for future cardiovascular disease. J Clin Endocrinol Metab (2002) 87:2013-7. doi: 10.1210/ jcem.87.5.8471

133. Salonen Jukka T, Salonen R. Ultrasonographically assessed carotid morphology and the risk of coronary heart disease. Arterioscler Thromb (1991) 11:1245-9. doi: 10.1161/01.ATV.11.5.1245

134. Burke GL, Evans GW, Riley WA, Sharrett AR, Howard G, Barnes RW, et al. Arterial wall thickness is associated with prevalent cardiovascular disease in middle-aged adults: the Atherosclerosis Riskin Communities (ARIC) Study. Stroke (1995) 26:386-91. doi: 10.1161/01.STR.26.3.386

135. Bots ML, Hoew AW, Koudstaal PJ, Hofman A. Grobbee DE. Common carotid intima-media thickness and risk of stroke and myocardial infarction: the Rotterdam Study. Circulation (1997) 96:1432-7. doi: 10.1161/ 01.CIR.96.5.1432

136. Chambless LE, Folsom AR, Clegg LX, Sharrett AR, Shahar E, Nieto FJ, et al. Carotid wall thickness is predictive of incident clinical stroke: the Atherosclerosis Risk in Communities (ARIC) study. Am J Epidemiol (2000) 151:478-87. doi: 10.1093/oxfordjournals.aje.a010233

137. Kuller LH, Shemanski L, Psaty BM, Borhani NO, Gardin J, Haan MN, et al. Subclinical disease as an independent risk factor for cardiovascular disease. Circulation (1995) 92:720-6. doi: 10.1161/01.CIR.92.4.720

138. O’Leary DH, Polak JF, Kronmal RA, Manolio TA, Burke GL, WolfsonSK Jr, et al. Carotid-artery intima and media thickness as a risk factor for 
myocardial infarction and stroke in older adults. $N$ Engl J Med (1999) 340:14-22. doi: 10.1056/NEJM199901073400103

139. Tonstad S, Joakimsen O, Stensland-Bugge E, Leren TP, Ose L, Russell D, et al. Risk factors related to carotid intima-media thickness and plaque in children with familial hypercholesterolemia and control subjects. Arterioscler Thromb Vasc Biol (1996) 16:984-91. doi: 10.1161/01.ATV.16.8.984

140. Chambless LE, Heiss G, Folsom AR, Rosamond W, Szkle M, Charrett AR, et al. Association of coronary heart disease incidence with carotid arterial wall thickness and major risk factors: the Atherosclerosis Risk in Communities (ARIC) Study, 1987-1993. Am J Epidemiol (1997) 146:48394. doi: 10.1093/oxfordjournals.aje.a009302

141. Folsom AR, Eckfeldt JH, Weitzman S, Jing M, Chambless LE, Barnes RW, et al. Relation of carotid artery wall thickness to diabetes mellitus, fasting glucose and insulin, body size, and physical activity. Stroke (1994) 25:66-73. doi: 10.1161/01.STR.25.1.66

142. Lassila HC, Tyrrell KS, Matthews KA, Wolfson SK, Kuller LH. Prevalence and determinants of carotid atherosclerosis in healthy postmenopausal women. Stroke (1997) 28:513-7. doi: 10.1161/01.STR.28.3.513

143. Sutton-Tyrrell K, Alcorn HG, Herzog H, Kelsey SF, Kuller LH. Morbidity, mortality, and antihypertensive treatment effects by extent of atherosclerosis in older adults with isolated systolic hypertension. Stroke (1995) 26:1319-24. doi: 10.1161/01.str.26.8.1319

144. Bonithon-Kopp C, Scarabin P-Y, Taquet A, Touboul P-J, Malmejac A, Guize L. Risk factors for early carotid atherosclerosis in mddle-aged French women. Arterioscler Thromb (1991) 11:966-72. doi: 10.1161/01.atv.11.4.966

145. Dobs AS, Nieto FJ, Szklo M, Barnes R, Sharrett AR, Ko W-J, et al. Risk factors for popliteal and carotid wall thicknesses in the atherosclerosis risk in communities (ARIC) study. Am J Epidemiol (1999) 150:1055-67. doi: 10.1093/oxfordjournals.aje.a009929

146. Folsom AR, Wu KK, Shahar E, Davis CEfor the Atherosclerosis Risk in Communities (ARIC) Study Investigators. Association of hemostatic variables with prevalent cardiovascular disease and asymptomatic carotid artery atherosclerosis. Arterioscler Thromb (1993) 13:1829-36. doi: 10.1161/ 01.atv.13.12.1829

147. Meyer ML, Malek AM, Wild RA, Korytkowski MT, Talbott EO. Carotid artery intima-media thickness in polycystic ovary syndrome:a systemic review and meta-analysis. Hum Reprod Update (2012) 18(2):122-26. doi: 10.1093/humupd/dmr046

148. Arad Y, Spadaro LA, Goodman K, Newstein D. Guerci AD 2000 Prediction of coronary events with electron beam computed tomography. J Am Coll Cardiol (2000) 36:1253-60. doi: 10.1016/S0735-1097(00)00872-X

149. Christian RC, Dumesic DA, Behrenbeck T, Oberg AL, Sheedy PF, Fitzpatrick LA. Prevalence and predictors of coronary artery calcification in women with polycystic ovary syndrome. J Clin Endocrinol Metab (2003) 88(6):2562-8. doi: 10.1210/jc.2003-030334

150. Talbott EO, Zborowski JV, Rager JR, Boudreaux MY, Edmundowicz DA, Guzick DS. Evidence for an association between metabolic cardiovascular syndrome and coronary and aortic calcification mong women with polycystic ovary syndrome. J Clin Endocrinol Metab (2004) 89(11):545461. doi: $10.1210 /$ jc.2003-032237

151. Shroff R, Kerchner A, Maifeld M, Van Beek EJ, Jagasia D, Dokras A. Young obese women with polycystic ovary syndrome have evidence of early coronary atherosclerosis. J Clin Endocrinol Metab (2007) 92(12):4609-14. doi: 10.1210/jc.2007-1343

152. Pierard M, Tassin A, Conotte S, Zouaoui Boudjeltia K, Legrand A. Sustained Intermittent Hypoxemia Induces Adiponectin Oligomers Redistribution and a Tissue-Specific Modulation of Adiponectin Receptor in Mice. Front Physiol (2019) 10:68. doi: 10.3389/fphys.2019.00068

153. Anuurad E, Tracy RP, Pearson TA, Kim K, Berglund L. Synergistic role of inflammation and insulin resistance as coronary artery disease risk factors in African Americans and Caucasians. Atherosclerosis (2009) 205:290-5. doi: 10.1016/j.atherosclerosis.2008.11.028

154. Repaci A, Gambineri A, Pasquali R. The role of low-grade inflammation in the polycystic ovary syndrome. Mol Cell Endocrinol (2011) 335(1):30-41. doi: 10.1016/j.mce.2010.08.002

155. Agarwal A, Gupta S, Sharma RK. Role of oxidative stress in female reproduction. Reprod Biol Endocrinol RBせE (2005) 3:28-8. doi: 10.1186/ $1477-7827-3-28$
156. Forman HJ, Fukuto JM, Torres M. Redox signaling: thiol chemistry defines which reactive oxygen and nitrogen species can act as second messengers. Am J Physiol Cell Physiol (2004) 287:C246-256. doi: 10.1152/ajpcell.00516.2003

157. Fujii H, Nakai K, Fukagawa M. Role of Oxidative Stress and Indoxyl Sulfate in Progression of Cardiovascular Disease in Chronic Kidney Disease. Ther Apheresis Dialysis (2011) 15:125-8. doi: 10.1111/j.1744-9987.2010.00883.x

158. Biondi R, Brancorsini S, Poli G, Egidi MG, Capodicasa E, Bottiglieri L, et al. Detection and scavenging of hydroxyl radical via D-phenylalanine hydroxylation in human fluids. Talanta (2018) 181:172-81. doi: 10.1016/ j.talanta.2017.12.084

159. Valko M, Rhodes CJ, Moncol J, Izakovic M, Mazur M. Free radicals, metals and antioxidants in oxidative stress-induced cancer. Chem Biol Interact (2006) 160:1-40. doi: 10.1016/j.cbi.2005.12.009

160. Sayre LM, Smith MA, Perry G. Chemistry and biochemistry of oxidative stress in neurodegenerative disease. Curr Med Chem (2001) 8:721-38. doi: 10.2174/0929867013372922

161. Birben E, Sahiner UM, Sackesen C, Erzurum S, Kalayci O. Oxidative stress and antioxidant defense. World Allergy Organ J (2012) 5:9-19. doi: 10.1097/ WOX.0b013e3182439613

162. Patel RP, McAndrew J, Sellak H, White CR, Jo H, Freeman BA, et al. Biological aspects of reactive nitrogen species. Biochim Biophys Acta (1999) 1411:385-400. doi: 10.1016/s0005-2728(99)00028-6

163. Halliwell B, Gutteridge JM, Cross CE. Free radicals, antioxidants, and human disease: where are we now? J Lab Clin Med (1992) 119:598-620. doi: 10.1016/ S0140-6736(94)92211-X

164. Pierce JD, Cackler AB, Arnett MG. Why should you care about free radicals? $R n$ (2004) 67:38-42; quiz 43.

165. Szczepańska M, Koźlik J, Skrzypczak J, Mikołajczyk M. Oxidative stress may be a piece in the endometriosis puzzle. Fertil Steril (2003) 79:1288-93. doi: 10.1016/s0015-0282(03)00266-8

166. Van Langendonckt A, Casanas-Roux F, Donnez J. Oxidative stress and peritoneal endometriosis. Fertil Steril (2002) 77:861-70. doi: 10.1016/s00150282(02)02959-x

167. Attaran M, Pasqualotto E, Falcone T, Goldberg JM, Miller KF, Agarwal A, et al. The effect of follicular fluid reactive oxygen species on the outcome of in vitro fertilization. Int J Fertil Women's Med (2000) 45:314-20.

168. Phaniendra A, Jestadi DB, Periyasamy L. Free radicals: properties, sources, targets, and their implication in various diseases. Indian J Clin Biochem IJCB (2015) 30:11-26. doi: 10.1007/s12291-014-0446-0

169. García-Sánchez A, Miranda-Díaz AG, Cardona-Muñoz EG. The Role of Oxidative Stress in Physiopathology and Pharmacological Treatment with Pro- and Antioxidant Properties in Chronic Diseases. Oxid Med Cell Longevity (2020) 2020:2082145-2082145. doi: 10.1155/2020/2082145

170. Papalou O, Victor VM, Diamanti-Kandarakis E. Oxidative Stress in Polycystic Ovary Syndrome. Curr Pharm Design (2016) 22:2709-22. doi: $10.2174 / 1381612822666160216151852$

171. Wallace DC. Mitochondrial DNA mutations in disease and aging. Environ Mol Mutagen (2010) 51:440-50. doi: 10.1002/em.20586

172. Khashchenko E, Vysokikh M, Uvarova E, Krechetova L, Vtorushina V, Ivanets T, et al. Activation of Systemic Inflammation and Oxidative Stress in Adolescent Girls with Polycystic Ovary Syndrome in Combination with Metabolic Disorders and Excessive Body Weight. J Clin Med (2020) 9 (5):1399. doi: $10.3390 / \mathrm{jcm} 9051399$

173. Sathyapalan T, Atkin SL. Mediators of inflammation in polycystic ovary syndrome in relation to adiposity. Mediators Inflamm (2010) 2010:758656. doi: $10.1155 / 2010 / 758656$

174. Repaci A, Gambineri A, Pasquali R. The role of low-grade inflammation in the polycystic ovary syndrome. Mol Cell Endocrinol (2011) 335:30-41. doi: 10.1016/j.mce.2010.08.002

175. Asemi Z, Samimi M, Tabassi Z, Shakeri H, Sabihi SS, Esmaillzadeh A. Effects of DASH diet on lipid profiles and biomarkers of oxidative stress in overweight and obese women with polycystic ovary syndrome: a randomized clinical trial. Nutr (Burbank Los Angeles County Calif) (2014) 30:1287-93. doi: 10.1016/j.nut.2014.03.008

176. Kazemi M, Jarrett BY, Vanden Brink H, Lin AW. Obesity, Insulin Resistance, and Hyperandrogenism Mediate the Link between Poor Diet Quality and Ovarian Dysmorphology in Reproductive-Aged Women. Nutrients (2020) 12(7):1953. doi: $10.3390 /$ nu12071953 
177. Tosatti JAG, Alves MT, Cândido AL, Reis FM, Araújo VE, Gomes KB. Influence of $\mathrm{n}-3$ fatty acid supplementation on inflammatory and oxidative stress markers in patients with polycystic ovary syndrome: a systematic review and meta-analysis. Br J Nutr (2020) 17:1-12. doi: 10.1017/s00071145 20003207

178. Talbott E, Guzick D, Clerici A, Berga S, Detre K, Weimer K, et al. Coronary heart disease risk factors in women with polycystic ovary syndrome. Arterioscler Thromb Vasc Biol (1995) 15:821-6. doi: 10.1161/01.atv.15.7.821

179. Sulaiman MA, Al-Farsi YM, Al-Khaduri MM, Saleh J, Waly MI. Polycystic ovarian syndrome is linked to increased oxidative stress in Omani women. Int J Womens Health (2018) 10:763-71. doi: 10.2147/IJWH.S166461

180. Hyderali BN, Mala K. Oxidative stress and cardiovascular complications in polycystic ovarian syndrome. Eur J Obstetr Gynecol Reprod Biol (2015) 191:15-22. doi: 10.1016/j.ejogrb.2015.05.005

181. Deanfield JE, Halcox JP, Rabelink TJ. Endothelial function and dysfunction: testing and clinical relevance. Circulation (2007) 115:1285-95. doi: 10.1161/ circulationaha.106.652859

182. Spritzer PM, Lecke SB, Satler F, Morsch DM. Adipose tissue dysfunction, adipokines, and low-grade chronic inflammation in polycystic ovary syndrome. Reprod (Cambridge England) (2015) 149:R219-27. doi: 10.1530/ rep-14-0435

183. Kelly CC, Lyall H, Petrie JR, Gould GW, Connell JM, Sattar N. Low grade chronic inflammation in women with polycystic ovarian syndrome. J Clin Endocrinol Metab (2001) 86:2453-5. doi: 10.1210/jcem.86.6.7580

184. Escobar-Morreale HF, Luque-Ramírez M, González F. Circulating inflammatory markers in polycystic ovary syndrome: a systematic review and metaanalysis. Fertil Steril (2011) 95:1048-58.e1041-1042. doi: 10.1016/ j.fertnstert.2010.11.036

185. Sathyapalan T, Kilpatrick ES, Coady AM, Atkin SL. The effect of atorvastatin in patients with polycystic ovary syndrome: a randomized double-blind placebo-controlled study. J Clin Endocrinol Metab (2009) 94:103-8. doi: 10.1210/jc.2008-1750

186. Webb MA, Mani H, Robertson SJ, Waller HL, Webb DR, Edwardson CL, et al. Moderate increases in daily step count are associated with reduced IL6 and CRP in women with PCOS. Endocrine Connect (2018) 7:1442-7. doi: $10.1530 /$ ec-18-0438

187. Herman R, Jensterle Sever M, Janez A, Dolzan V. Interplay between Oxidative Stress and Chronic Inflammation in PCOS: The Role of Genetic Variability in PCOS Risk and Treatment Responses. London, UK: IntechOpen (2019). doi: 10.5772/intechopen.88698

188. Murri M, Luque-Ramírez M, Insenser M, Ojeda-Ojeda M, Escobar-Morreale HF. Circulating markers of oxidative stress and polycystic ovary syndrome (PCOS): a systematic review and meta-analysis. Hum Reprod Update (2013) 19:268-88. doi: 10.1093/humupd/dms059

189. Tyagi N, Sedoris KC, Steed M, Ovechkin AV, Moshal KS, Tyagi SC. Mechanisms of homocysteine-induced oxidative stress. Am J Physiol Heart Circ Physiol (2005) 289:H2649-56. doi: 10.1152/ajpheart.00548.2005

190. Shenoy V, Mehendale V, Prabhu K, Shetty R, Rao P. Correlation of serum homocysteine levels with the severity of coronary artery disease. Indian J Clin Biochem IJCB (2014) 29:339-44. doi: 10.1007/s12291-013-0373-5
191. Veeranna V, Zalawadiya SK, Niraj A, Pradhan J, Ference B, Burack RC, et al. Homocysteine and reclassification of cardiovascular disease risk. J Am Coll Cardiol (2011) 58:1025-33. doi: 10.1016/j.jacc.2011.05.028

192. Mangge H, Becker K, Fuchs D, Gostner JM. Antioxidants, inflammation and cardiovascular disease. World J Cardiol (2014) 6:462-77. doi: 10.4330/ wjc.v6.i6.462

193. Pang X, Liu J, Zhao J, Mao J, Zhang X, Feng L, et al. Homocysteine induces the expression of C-reactive protein via NMDAr-ROS-MAPK-NF- $\kappa \mathrm{B}$ signal pathway in rat vascular smooth muscle cells. Atherosclerosis (2014) 236:7381. doi: 10.1016/j.atherosclerosis.2014.06.021

194. Zhang S, Bai YY, Luo LM, Xiao WK, Wu HM, Ye P. Association between serum homocysteine and arterial stiffness in elderly: a community-based study. J Geriatric Cardiol JGC (2014) 11:32-8. doi: 10.3969/j.issn.16715411.2014.01.007

195. Faeh D, Chiolero A, Paccaud F. Homocysteine as a risk factor for cardiovascular disease: should we (still) worry about? Swiss Med Weekly (2006) 136:745-56. doi: 2006/47/smw-11283

196. Sathyapalan T, David R, Gooderham NJ, Atkin SL. Increased expression of circulating miRNA-93 in women with polycystic ovary syndrome may represent a novel, non-invasive biomarker for diagnosis. Sci Rep (2015) 5:16890. doi: 10.1038/srep16890

197. Chen B, Xu P, Wang J, Zhang C. The role of MiRNA in polycystic ovary syndrome (PCOS). Gene (2019) 706:91-6. doi: 10.1016/j.gene.2019.04.082

198. Lu H, Buchan R, Cook S, Lu H, Buchan RJ, Cook SA. MicroRNA-223 regulates Glut4 expression and cardiomyocyte glucose metabolism. Cardiovasc Res 86: 410-420. Cardiovasc Res (2010) 86:410-20. doi: $10.1093 / \mathrm{cvr} / \mathrm{cvq} 010$

199. Butler AE, Ramachandran V, Hayat S, Dargham SR, Cunningham TK, Benurwar M, et al. Expression of microRNA in follicular fluid in women with and without PCOS. Sci Rep (2019) 9:16306. doi: 10.1038/s41598-019-52856-5

200. Deswal R, Dang AS. Dissecting the role of micro-RNAs as a diagnostic marker for polycystic ovary syndrome: a systematic review and meta-analysis. Fertil Steril (2020) 113:661-9.e662. doi: 10.1016/j.fertnstert.2019.11.001

201. Macfarlane L-A, Murphy PR. MicroRNA: Biogenesis, Function and Role in Cancer. Curr Genomics (2010) 11:537-61. doi: 10.2174/138920210793175895

Conflict of Interest: PA was employed by the company Antisel RO SRL, Division of Molecular Diagnostics and Biotechnology, Bucharest, Romania.

The remaining authors declare that the research was conducted in the absence of any commercial or financial relationships that could be construed as a potential conflict of interest.

Copyright (c) 2021 Duică, Dănilă, Boboc, Antoniadis, Condrat, Onciul, Suciu, Creţoiu, Varlas and Crețoiu. This is an open-access article distributed under the terms of the Creative Commons Attribution License (CC BY). The use, distribution or reproduction in other forums is permitted, provided the original author(s) and the copyright owner(s) are credited and that the original publication in this journal is cited, in accordance with accepted academic practice. No use, distribution or reproduction is permitted which does not comply with these terms. 